\begin{tabular}{|c|c|}
\hline Title & Formation of chiral CO polyhedral crystals on icy interstellar grains \\
\hline Author(s) & $\begin{array}{l}\text { Kouchi, A kira; T suge, Masashi; Hama, T etsuya; Niinomi, Hiromasa; Nakatani, Naoki; Shimoni shi, T akashi; Oba, } \\
\text { Y asuhiro; Kimura, Y uki; Sirono, Sin-iti; Okuzumi, Satoshi; Momose, Munetake; Furuya, Kenji; W atanabe, Naoki }\end{array}$ \\
\hline Citation & $\begin{array}{l}\text { Monthly notices of the royal astronomical society, 505(1), 1530-1542 } \\
\text { https://doi.org/10.1093/mnras/stab1173 }\end{array}$ \\
\hline Issue Date & 2021-07 \\
\hline Doc URL & http:/hdl.handle.net/2115/82505 \\
\hline Rights & $\begin{array}{l}\text { This article has been accepted for publication in Monthly notices of the royal astronomical society @:2021 A kira } \\
\text { Kouchi Published by Oxford University Press on behalf of The Royal A stronomical Society. A II rights reserved. }\end{array}$ \\
\hline Type & article \\
\hline File Information & Monthly notices of the royal astronomical society505 (1)_1530-1542.pdf \\
\hline
\end{tabular}

Instructions for use 


\title{
Formation of chiral CO polyhedral crystals on icy interstellar grains
}

\author{
Akira Kouchi ${ }^{\circledR},{ }^{1 \star}$ Masashi Tsuge ${ }^{\circledR},{ }^{1}$ Tetsuya Hama, ${ }^{2}$ Hiromasa Niinomi, ${ }^{3}$ Naoki Nakatani, ${ }^{4}$ \\ Takashi Shimonishi, ${ }^{5}$ Yasuhiro Oba ${ }^{\circ},{ }^{1}$ Yuki Kimura, ${ }^{1}$ Sin-iti Sirono, ${ }^{6}$ Satoshi Okuzumi, ${ }^{7}$ \\ Munetake Momose, ${ }^{8}$ Kenji Furuya $^{\oplus 9}$ and Naoki Watanabe ${ }^{1}$ \\ ${ }^{1}$ Institute of Low-Temperature Science, Hokkaido University, Sapporo, Hokkaido 060-0819, Japan \\ ${ }^{2}$ Komaba Institute for Science, The University of Tokyo, Meguro, Tokyo 153-8902, Japan \\ ${ }^{3}$ Institute for Materials Research, Tohoku University, Sendai, Miyagi 980-8577, Japan \\ ${ }^{4}$ Department of Chemistry, Graduate School of Science and Engineering, Tokyo Metropolitan University, Hachioji, Tokyo 192-0397, Japan \\ ${ }^{5}$ Center for Transdisciplinary Research, Niigata University, Niigata 950-2181, Japan \\ ${ }^{6}$ Earth and Environmental Sciences, Graduate School of Environmental Studies, Nagoya University, Nagoya, Aichi 464-8601, Japan \\ ${ }^{7}$ Department of Earth and Planetary Sciences, Tokyo Institute of Technology, Meguro, Tokyo 152-8551, Japan \\ ${ }^{8}$ College of Science, Ibaraki University, Mito, Ibaraki 310-8512, Japan \\ ${ }^{9}$ National Astronomical Observatory of Japan, Osawa 2-21-1, Mitaka, Tokyo 181-8588, Japan
}

Accepted 2021 April 13. Received 2021 February 20; in original form 2020 August 17

\section{ABSTRACT}

The crystallinity and morphology of solid carbon monoxide (CO) on icy interstellar grains were examined by observing the deposition, crystallization, and UV and electrons irradiation of solid CO using transmission electron microscopy. Herein, we found that solid $\mathrm{CO}$ deposited in molecular clouds was crystalline, and that even if amorphous $\mathrm{CO}$ was deposited, amorphous $\mathrm{CO}$ crystallized within $10^{3} \mathrm{yr}$ at $10 \mathrm{~K}$. Conversely, crystalline $\mathrm{CO}$ was not amorphized by UV rays or electron beam at $10 \mathrm{~K}$. These results indicated the occurrence of chiral crystalline $\mathrm{CO}$ instead of amorphous $\mathrm{CO}$ in space. Furthermore, the large surface diffusion coefficients of $\mathrm{CO}$ on eamorphous $\mathrm{H}_{2} \mathrm{O}$ and crystalline $\mathrm{CO}$ at $10 \mathrm{~K}$ facilitated the morphological equilibration of crystalline $\mathrm{CO}$. Bad wetting of crystalline $\mathrm{CO}$ with amorphous $\mathrm{H}_{2} \mathrm{O}$ proved that the morphology of the ice grains was not spherical with an onion-like structure, as hitherto assumed, but rather it was a polyhedral crystalline $\mathrm{CO}$ attached to amorphous $\mathrm{H}_{2} \mathrm{O}$. This has important implications for phenomena associated with the collision and subsequent sticking between ice grains, surface chemical reactions, non-thermal desorption of molecules and the origin of homochirality in interstellar biomolecules.

Key words: astrochemistry-method: laboratory: solid-state-ISM: dust.

\section{INTRODUCTION}

The morphology of icy interstellar grains is important for various astrophysical and astrochemical phenomena as it governs collision and sticking/disruption processes (Dominik \& Tielens 1997; Poppe, Blum \& Henning 2000; Musiolik et al. 2016), sintering (Sirono 1999), and the optical properties (Li \& Greenberg 1997) of icy interstellar grains. However, the proposed models for ice-grain aggregates (Dominik \& Tielens 1997; Sirono 1999; Wada et al. 2007) usually assume that the grains are spheres or spheroids containing an onion-like structure with an $\mathrm{H}_{2} \mathrm{O}$-rich ice mantle that is, in turn, covered by a CO-rich ice mantle (Ehrenfreund et al. 1998; Sirono 2011; Boogert, Gerakines \& Whittet 2015; O”berg 2016; Musiolik et al. 2016; Okuzumi et al. 2016). If ice grains are amorphous, the morphology of the icy layer follows the shape of the refractory core grain due to the small self-diffusion coefficients. Conversely, if some ice components are crystalline, their morphologies preferentially adopted polyhedral structures rather than uniform layers due to their large self-diffusion coefficients. Sticking or fragmentation processes occur randomly if the grain's surface is covered with

^E-mail: kouchi@lowtem.hokudai.ac.jp polyhedral structures, regardless of the collision velocities (Poppe et al. 2000). In this case, precisely knowing the crystallinity of the ice grains is essential, whether the grains are amorphous or crystalline. Furthermore, the ice grains' crystallinity provides information on their thermal history.

In the case of $\mathrm{H}_{2} \mathrm{O}$ ice, the conditions for the deposition and preservation of amorphous $\mathrm{H}_{2} \mathrm{O}\left(\mathrm{am}-\mathrm{H}_{2} \mathrm{O}\right)$ have been examined both theoretically and experimentally (Kouchi et al. 1994; Ciesla 2014). Although we usually use ' $a-$ ' as the abbreviation for amorphous, we will not adhere to this convention in the present paper to avoid any confusion between a-CO and $\alpha-\mathrm{CO}$ (one of the polymorphs of crystalline CO). Instead, we will use 'am-' to refer to am- $\mathrm{H}_{2} \mathrm{O}$ or am-CO. Also, crystalline polymorphs are usually distinguished using Greek letters (e.g. $\alpha$ - $\mathrm{CO}$ and $\gamma-\mathrm{CH}_{3} \mathrm{OH}$ ) or roman numerals (e.g. $\mathrm{CO}_{2} \mathrm{IV}$ and ice $\mathrm{XI}$ ). The formation of am- $\mathrm{H}_{2} \mathrm{O}$ during deposition occurs when the flux of the water vapour is larger than the critical value threshold, and the preservation of am- $\mathrm{H}_{2} \mathrm{O}$ is achieved when temperature is lower than a critical value. The latter condition could be verified via experiments on the temperature dependence of crystallization as a function of time (Kouchi et al. 1994; Jenniskens \& Blake 1996; Baragiola 2003; Mastrapa, Grundy \& Gudipati 2013). Another important factor influencing the crystallinity of $\mathrm{H}_{2} \mathrm{O}$ ice is radiation-induced amorphization (Famá et al. 2010). It has been 
(a)

(b)

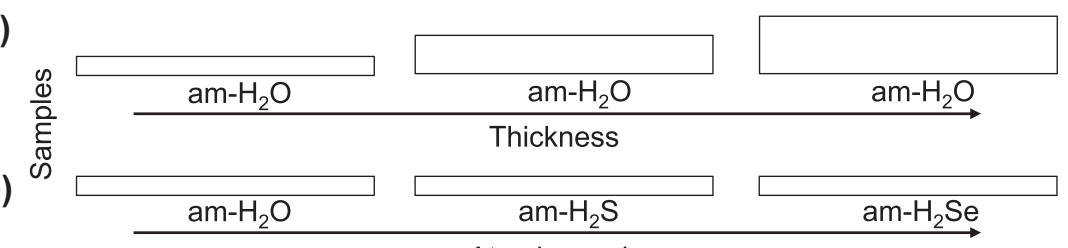

(c)

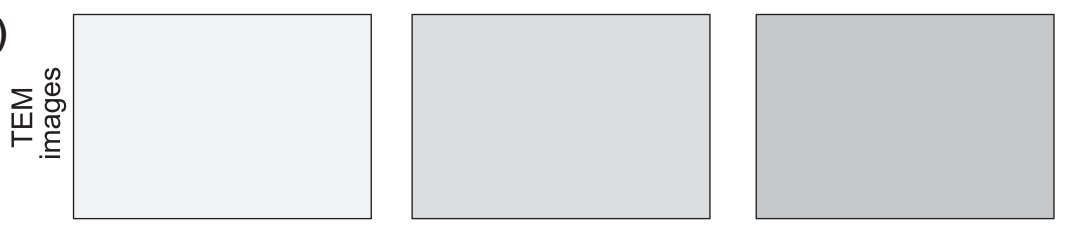

(d)

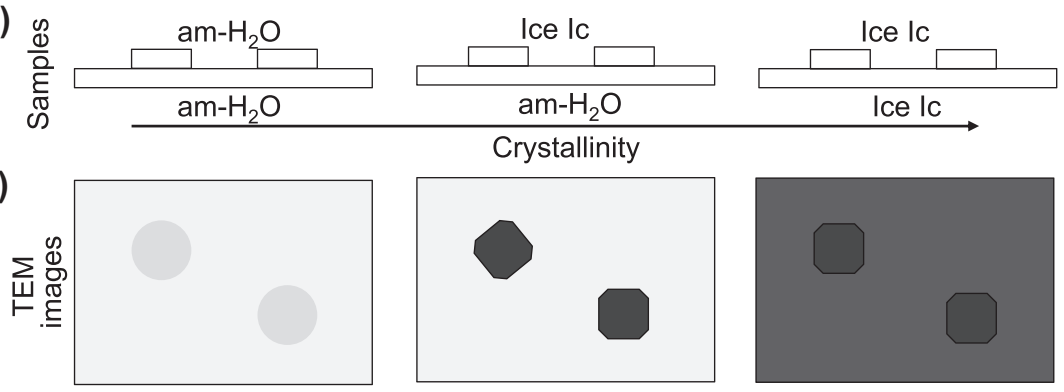

Figure 1. Schematic illustrations on the brightness of TEM images of amorphous materials with increasing thickness or atomic number (a-c) and the effect of crystallinity $(\mathrm{d}, \mathrm{e})$. The former $(\mathrm{a}-\mathrm{c})$ is attributed to the scattering contrast and the latter $(\mathrm{d}, \mathrm{e})$ is attributed to the diffraction contrast.

shown that UV irradiation (Kouchi \& Kuroda 1990; Leto \& Baratta 2003), electron beam (Heide 1984; Heide \& Zeitler 1985), and other high-energy particle bombardments (Strazzula et al. 1992; Moore \& Hudson 1992) facilitate the amorphization of ice I crystals at temperatures lower than $\sim 70 \mathrm{~K}$. Therefore, UV rays or other particle irradiation sources obscure the thermal history of ice I crystals.

An important factor controlling the morphology of icy interstellar grains is substrate wetting. When the wetting is complete, the ice crystals adopt a uniform film configuration, regardless of the inherent degree of crystallinity. Conversely, bad wetting causes the formation of 3D ice islands. However, research on wetting is extremely limited in astrophysically relevant systems. Noble et al. (2012) investigated the adsorption of $\mathrm{CO}, \mathrm{CO}_{2}$, and $\mathrm{O}_{2}$ on non-porous am- $\mathrm{H}_{2} \mathrm{O}$, crystalline ice, and $\mathrm{SiO}_{2}$, and quantitatively discussed wetting. There has been no study on the wetting analysis of $\mathrm{CO}$ during further growth.

Since $\mathrm{CO}_{2}$ and $\mathrm{CO}$ are abundant ice components, after $\mathrm{H}_{2} \mathrm{O}$, in interstellar molecular clouds (Gibb et al. 2004; Boogert et al. 2015), understanding the crystallinity of $\mathrm{CO}_{2}$ and $\mathrm{CO}$ is essential for discussing the thermal history of low-temperature interstellar grains. The crystallinity of solid $\mathrm{CO}_{2}$ has been examined in detail via infrared spectroscopy (Escribano et al. 2013; Gerakines \& Hudson 2015; Baratta \& Palumbo 2017; He \& Vidali 2018) and transmission electron microscopy (TEM) (Kouchi et al. 2020). Additionally, the effect of UV and electron beam irradiation on solid $\mathrm{CO}_{2}$ was investigated by Tsuge et al. (2020). To date, there are no IR studies on the nature of amorphous CO (am-CO). Although Kouchi (1990) observed the crystallization of am-CO via reflection highenergy electron diffraction, observations were limited at a specific heating rate. Kouchi et al. (2020) determined the extent and factors influencing $\mathrm{CO}$ deposition on am- $\mathrm{H}_{2} \mathrm{O}$ via TEM and determined the associated activation energy of the surface diffusion of $\mathrm{CO}$ and $\mathrm{CO}_{2}$ on am- $\mathrm{H}_{2} \mathrm{O}$. However, they used only porous am- $\mathrm{H}_{2} \mathrm{O}$ as a substrate and not non-porous am- $\mathrm{H}_{2} \mathrm{O}$. Furthermore, no findings on the conditions governing the formation of am-CO and crystalline $\mathrm{CO}$ were discussed. In light of the above-mentioned circumstances, a systematic investigation of the described processes is highly desirable, particularly for understanding the deposition of $\mathrm{CO}$, the crystallization of am- $\mathrm{CO}$ on astrophysically relevant substrates like porous and non-porous am- $\mathrm{H}_{2} \mathrm{O}$, and the radiation-induced amorphization of crystalline CO. This investigation would help to define the crystallinity of solid CO. Furthermore, the processes and mechanisms governing the wetting of $\alpha$-CO using am- $\mathrm{H}_{2} \mathrm{O}$ should also be investigated to determine the morphology of $\alpha-\mathrm{CO}$ on am$\mathrm{H}_{2} \mathrm{O}$ grains.

\section{EXPERIMENTAL}

\subsection{Transmission electron microscopy}

Although a modern transmission electron microscope has various modes, imaging and electron diffraction are its most valuable and widely used techniques. High-energy electron beam and electromagnetic lenses enable us to create an image with resolution down to nm-scale. In general, the brightness of TEM images of amorphous materials decreases from bright (pale grey) to dark (dark grey) with increasing thickness or atomic numbers owing to the scattering contrast, as shown in Figs 1(a)-(c) (Reimer \& Kohl 2008, chapter 6). The brightness of crystalline samples (ice Ic in Figs 1d and e) is much darker (black) than that of am- $\mathrm{H}_{2} \mathrm{O}$ (pale grey) owing to the diffraction contrast (Reimer \& Kohl 2008, chapter 9). Therefore, the detection of crystals on amorphous substrates (centre image of Fig. 1e) is easier than those of amorphous materials on amorphous substrates and crystals on crystalline substrates, as shown in left and right images in Fig. 1(e), respectively. Electron diffraction patterns provide information not only on the crystallinity, amorphous, 
or crystalline but also on crystal structures. These two modes, imaging and electron diffraction, have advantages over the generally used technique in laboratory astrophysics and astrochemistry, such as optical spectroscopy and temperature-programmed desorption method. Only few works using TEM have been performed in these fields (e.g. Jenniskens \& Blake 1996). As commercially available TEM uses high-vacuum pumping system, the pressure attained is only $10^{-5} \mathrm{~Pa}$ order. In this situation, residual water vapour condenses onto the low temperature substrate and it becomes extremely difficult to observe the ice samples. Therefore, we developed a JEM-2100VL ultra-high vacuum (UHV)-TEM (JEOL) for the in situ observation of ices (Kouchi et al. 2016, 2020; Tachibana et al. 2017).

A column of the UHV-TEM was evacuated using five ion pumps. The pressure between the specimen chamber and the ion pump was $\sim 1 \times 10^{-6} \mathrm{~Pa}$. The pressure near the specimen was kept lower than $\sim 1 \times 10^{-6} \mathrm{~Pa}$ as the specimen was surrounded by a liquid nitrogen shroud. We used a Gatan ULTST liquid He cooling holder for sample cooling procedures. A 5-nm-thick, non-porous amorphous Si (amSi) film (SiMPore Inc. US100-A05Q33) was used as the substrate for sample deposition. There were three ICF 70 ports for in situ studies, which were directed at the specimen's surface at an incident angle of $55^{\circ}$. One of the ports was used for sample deposition; a Ti gas inlet tube with a $0.4-\mathrm{mm}$ inner diameter connected to variable-leak valve was faced to the substrate. In another port, a $30-\mathrm{W} \mathrm{D}_{2}$ lamp (Hamamatsu, L7293) was also equipped.

Damage to the samples caused by the electron beam was avoided by employing a low-dose technique (Tachibana et al. 2017) using an $80-\mathrm{kV}$ accelerating voltage, very weak electron beam intensity of $6 \times 10^{-3}$ electrons $\AA^{-2} \mathrm{~s}^{-1}$ at the sample position with $\times 50000$ and low-magnification observation using a Gatan ES500W CCD camera. All electron diffraction patterns were taken within a 700-nm radius of the central portion of the TEM images unless otherwise noted.

\subsection{Experimental protocol}

Experiments were performed following the protocol described below.

The CO deposition experiment was conducted by first making a $\sim 10$-nm-thick am- $\mathrm{H}_{2} \mathrm{O}$ layer on the am-Si substrate.

Porous am- $\mathrm{H}_{2} \mathrm{O}$ was made via vapour deposition with a deposition rate of $\sim 8 \mathrm{~nm} \mathrm{~min}^{-1}$ at $\sim 10 \mathrm{~K}$. For non-porous am- $\mathrm{H}_{2} \mathrm{O}$, porous am$\mathrm{H}_{2} \mathrm{O}$ was annealed at $100 \mathrm{~K}$ for $5 \mathrm{~min}$. Then, $\mathrm{CO}$ was deposited onto the am- $\mathrm{H}_{2} \mathrm{O}$ with a deposition rate of $\sim 1 \mathrm{~nm} \mathrm{~min}$ m $^{-1}$ (corresponding flux: $\sim 4 \times 10^{13} \mathrm{CO}$ molecules $\mathrm{cm}^{-1} \mathrm{~s}^{-1}$ ) at 10-20 K. We observed deposition process in situ using UHV-TEM, as previously reported by Kouchi et al. (2020).

The crystallization experiment was performed by first making a $\sim 20$-nm-thick layer of porous or non-porous am- $\mathrm{H}_{2} \mathrm{O}$ onto the substrate, followed by the deposition of a 20-nm-thick am-CO layer onto the am- $\mathrm{H}_{2} \mathrm{O}$ layer at a deposition rate of $\sim 1 \mathrm{~nm} \mathrm{~min}{ }^{-1}$. After deposition of am-CO at $10 \mathrm{~K}$, the sample was rapidly heated (at a rate of $\sim 40 \mathrm{~K} \mathrm{~min}^{-1}$ ) to $15-25 \mathrm{~K}$, and crystallization process was observed in situ at the desired temperatures using UHV-TEM. The timescale of crystallization is defined as the time required to visually see the 100 per cent crystallization of am-CO (e.g. Kouchi et al. 1994). Although detecting the onset of crystallization was not extremely challenging using TEM, determining the end-point of crystallization proved rather difficult (Jenniskens \& Blake 1996; Mastrapa et al. 2013) unlike IR spectroscopy applied to the crystallization of am$\mathrm{H}_{2} \mathrm{O}$ (e.g. Schmitt et al. 1989; Maté, Rodoríguez-Lazcano \& Herreo 2012). This is because the detection of a small amount of remaining am-CO in $\alpha-\mathrm{CO}$ via TEM is considerably difficult. Therefore, our measurement of the crystallization time-scales might have errors of about one order of magnitude.

The first steps of the UV and electron beam irradiation experiments entailed the direct deposition of $\mathrm{CO}$ onto the am-Si film to avoid contamination via $\mathrm{H}_{2} \mathrm{O}$. Both am-CO and $\alpha-\mathrm{CO}$ were deposited with a deposition rate of $\sim 1 \mathrm{~nm} \mathrm{~min}{ }^{-1}$ at $10 \mathrm{~K}$ and $19 \mathrm{~K}$, respectively. UV rays emitted from the $30-\mathrm{W} \mathrm{D}_{2}$ lamp in the range of $115-400 \mathrm{~nm}$ was used as UV source. Although we could not measure the UV flux at the sample position in TEM, the UV flux measured using another vacuum chamber equipped with a Si-photodiode (IRD, AXUV-100 G) was $\sim 2 \times 10^{13}$ photons $\mathrm{cm}^{-2} \mathrm{~s}^{-1}$ before setting the lamp for TEM. The UV rays were collimated using a mirror-finished pure Al-collimator, which might have affected the UV flux at the sample's position. We observed the UV irradiation processes in situ using the UHV-TEM.

For the electron beam irradiation experiments, normally weak and enlarged electron beam was strengthened and focused to $5-10 \mu \mathrm{m}$ in diameter. The intensity of the electron beam was roughly measured using a conventional Faraday cup equipped in the UHV-TEM. We observed the samples just before and after the irradiation using the enlarged electron beam.

\section{RESULTS}

\subsection{Crystallinity and morphology of solid CO during deposition}

Fig. 2 compares the $\mathrm{CO}$ deposition process at $19 \mathrm{~K}$ on porous and non-porous am- $\mathrm{H}_{2} \mathrm{O}$. The TEM images after the appearance of $\mathrm{CO}$ crystals (black images: 4.5, 6 min in Fig. 2a, and 5, 6 min in Fig. 2b) clearly show that the $\mathrm{CO}$ crystals $(\alpha-\mathrm{CO})$ did not grow as uniform films but rather as 3D islands regardless of the porosity of am$\mathrm{H}_{2} \mathrm{O}$ as schematically noted beneath the TEM images. These results indicated that $\alpha-\mathrm{CO}$ hardly wets am- $\mathrm{H}_{2} \mathrm{O}$ regardless of the porosity of am- $\mathrm{H}_{2} \mathrm{O}$.

The number density of $\alpha$-CO islands on non-porous am- $\mathrm{H}_{2} \mathrm{O}$ is smaller than that on porous am- $\mathrm{H}_{2} \mathrm{O}$, suggesting larger surface diffusion coefficient of $\mathrm{CO}$ on non-porous am- $\mathrm{H}_{2} \mathrm{O}$. To elucidate this finding, we observed the $\mathrm{CO}$ deposition process at $10-20 \mathrm{~K}$ on nonporous am- $\mathrm{H}_{2} \mathrm{O}$, as shown in Fig. 3. It is clear that with decreasing substrate temperature, the number density of $\alpha$-CO islands increased and that the crystalline sizes decreased. At lower temperatures, the formation of uniform am-CO film was observed as shown in Fig. 3(d). This transition temperature on non-porous am- $\mathrm{H}_{2} \mathrm{O}$ lies between 11.5 and $14 \mathrm{~K}$, which is lower than that on porous am- $\mathrm{H}_{2} \mathrm{O}$, between 14 and $18 \mathrm{~K}$.

From the saturated number density of $\alpha-\mathrm{CO}$, mean distances between crystalline islands and mean diffusion distances $X$ of $\mathrm{CO}$ on non-porous am- $\mathrm{H}_{2} \mathrm{O}$ were derived through the method of Kouchi et al. (2020). Fig. 4 shows the plot of $\ln X$ versus $1 / T$, whose slope corresponds to $E_{\mathrm{sd}} / 2 R$ where $E_{\mathrm{sd}}$ the activation energy of surface diffusion of CO, $T$ temperature, and $R$ the gas constant (Kouchi et al. 2020). We obtained the $E_{\mathrm{sd}}$ of $\mathrm{CO}$ on non-porous am- $\mathrm{H}_{2} \mathrm{O}$ of 200 $\pm 40 \mathrm{~K}$. This value is smaller than $E_{\text {sd }}$ of $\mathrm{CO}$ on porous am- $\mathrm{H}_{2} \mathrm{O}$ of $350 \pm 50 \mathrm{~K}$. Noble et al. (2012) measured the adsorption energy of $\mathrm{CO}$ on non-porous am- $\mathrm{H}_{2} \mathrm{O}, 828 \mathrm{~K} . E_{\mathrm{sd}}$ of $\mathrm{CO}$ on non-porous am- $\mathrm{H}_{2} \mathrm{O}$ obtained in this study is 0.24 of this value.

\subsection{Crystallization of am-CO}

Fig. 5 shows an example of am-CO crystallization on (a) porous am- $\mathrm{H}_{2} \mathrm{O}$ and (b) non-porous am- $\mathrm{H}_{2} \mathrm{O}$. The TEM images of solid $\mathrm{CO}$ deposited at $10 \mathrm{~K}$ showed uniform films and the electron diffraction pattern was halo, indicating that these samples were 


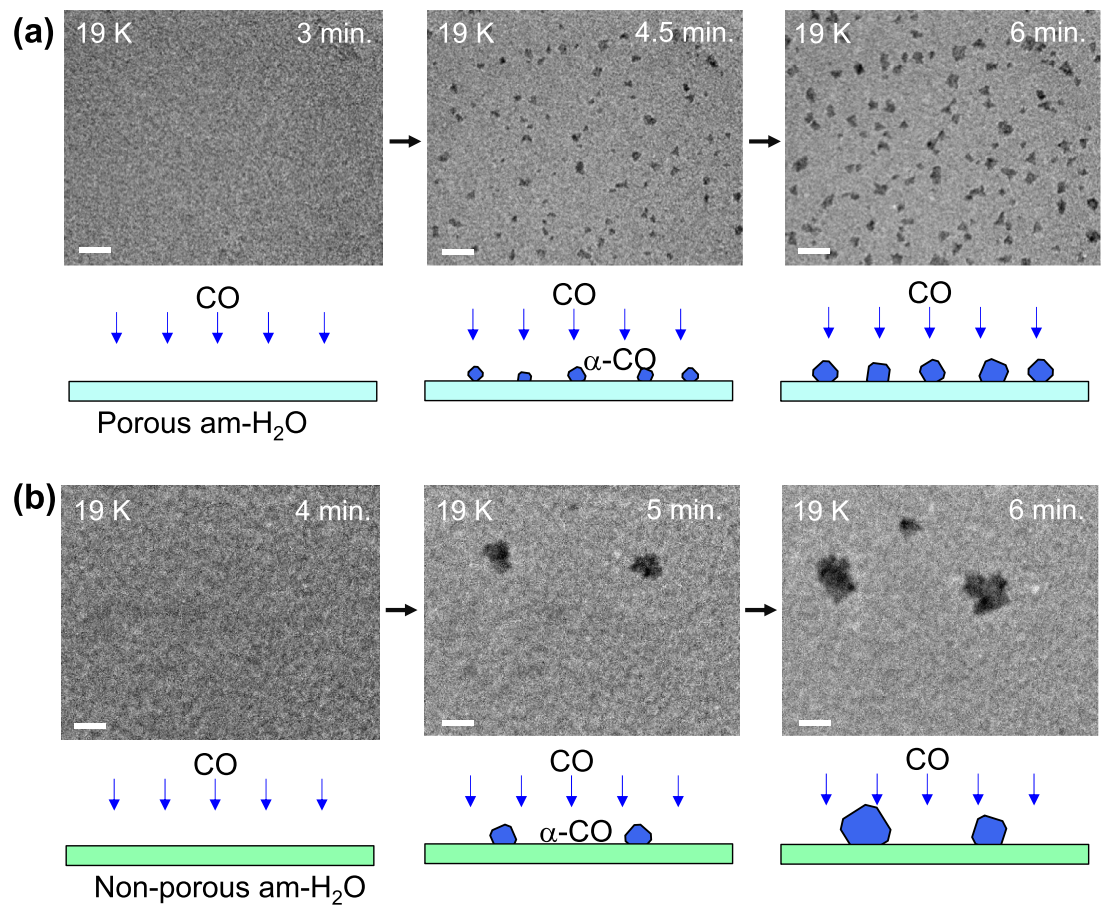

Figure 2. In situ TEM observation and corresponding schematics of the $\mathrm{CO}$ deposition process at $19 \mathrm{~K}$ on porous am- $\mathrm{H}_{2} \mathrm{O}$ (a) and non-porous am- $\mathrm{H}_{2} \mathrm{O}$ (b). The times shown were noted after the start of the $\mathrm{CO}$ deposition process. Thin blue arrows labelled $\mathrm{CO}$ represent impinging $\mathrm{CO}$ gas onto the substrates. The sharply contrasting (black) images are the CO crystals. All scale bars are $500 \mathrm{~nm}$.
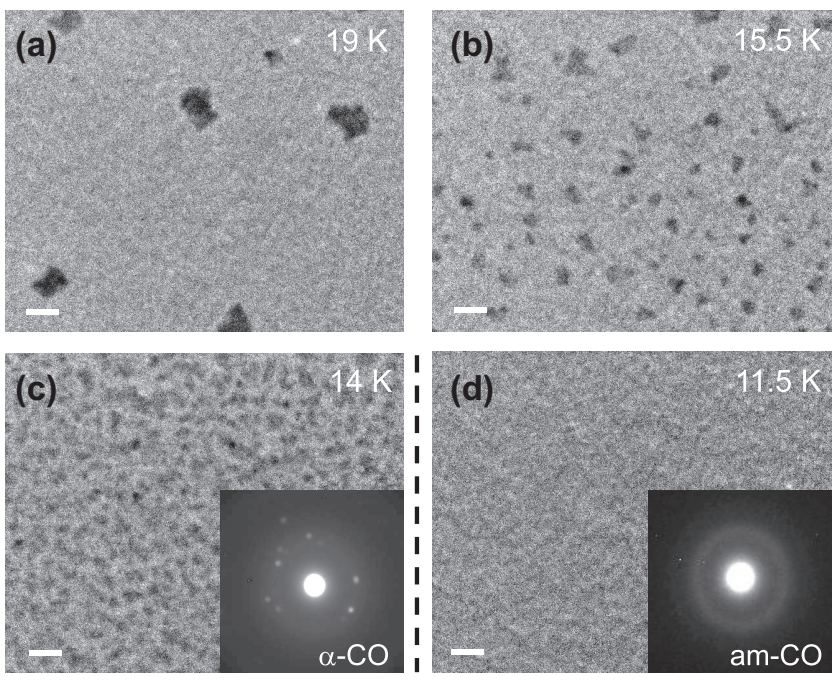

Figure 3. TEM images after the saturation of number densities of $\alpha$-CO during $\mathrm{CO}$ deposition at $11.5-19 \mathrm{~K}$ on non-porous am- $\mathrm{H}_{2} \mathrm{O}$. The corresponding electron diffraction patterns are shown for some TEM images. At temperatures higher than the critical temperature shown by broken line, $\alpha$-CO were formed. Conversely, at temperatures lower than the critical temperature, am-CO was deposited. All scale bars are $500 \mathrm{~nm}$.

am-CO. The TEM images and a corresponding electron diffraction pattern obtained at $24.5 \mathrm{~K}$ showed the presence of CO crystals ( $\alpha$ $\mathrm{CO}$ ). The image taken at $0.2 \mathrm{~min}$ and $24.5 \mathrm{~K}$ contained uniformed crystals that were $\sim 50 \mathrm{~nm}$ in size (Fig. $5 \mathrm{a}$ ), and that at $1 \mathrm{~min}$ and $24 \mathrm{~K}$ $\sim 200 \mathrm{~nm}$ in size (Fig. 5b).

The images taken after $3 \mathrm{~min}$ at 24.5 (Fig. 5a) and $24 \mathrm{~K}$ (Fig. 5b) contained only specific crystals that had grown $\sim 200 \mathrm{~nm}$ and

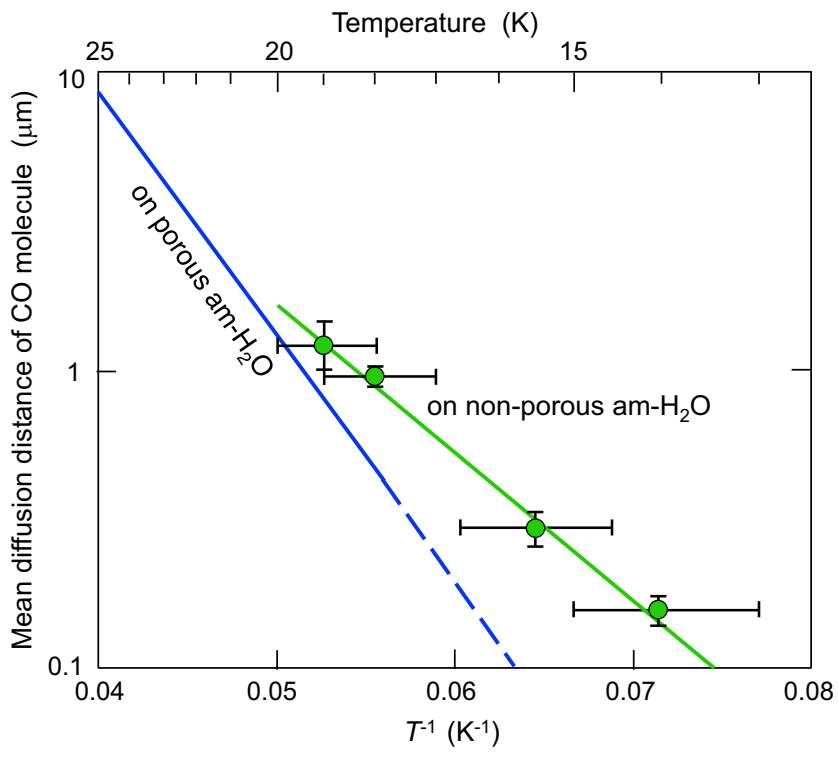

Figure 4. Plot of the mean diffusion distance of $\mathrm{CO}$ on non-porous am- $\mathrm{H}_{2} \mathrm{O}$ (green circles and line) and that of porous am- $\mathrm{H}_{2} \mathrm{O}$ (blue line, Kouchi et al. 2020) versus inverse of temperature. From the saturated number densities of crystals in Fig. 3, mean diffusion distances are calculated by the method of Kouchi et al. (2020).

$\sim 400 \mathrm{~nm}$ in size, respectively, whereas the other crystals remained unchanged in size or had shrunken via Ostwald ripening (Voorhees 1985; Bhakta \& Ruckenstein 1995). If we consider the grains in different sizes coexisting during the phase transformation process, larger grains grow, whereas smaller grains shrink. This phenomenon proceeds because smaller grains are thermodynamically unstable 
(a) $10 \mathrm{~K}$
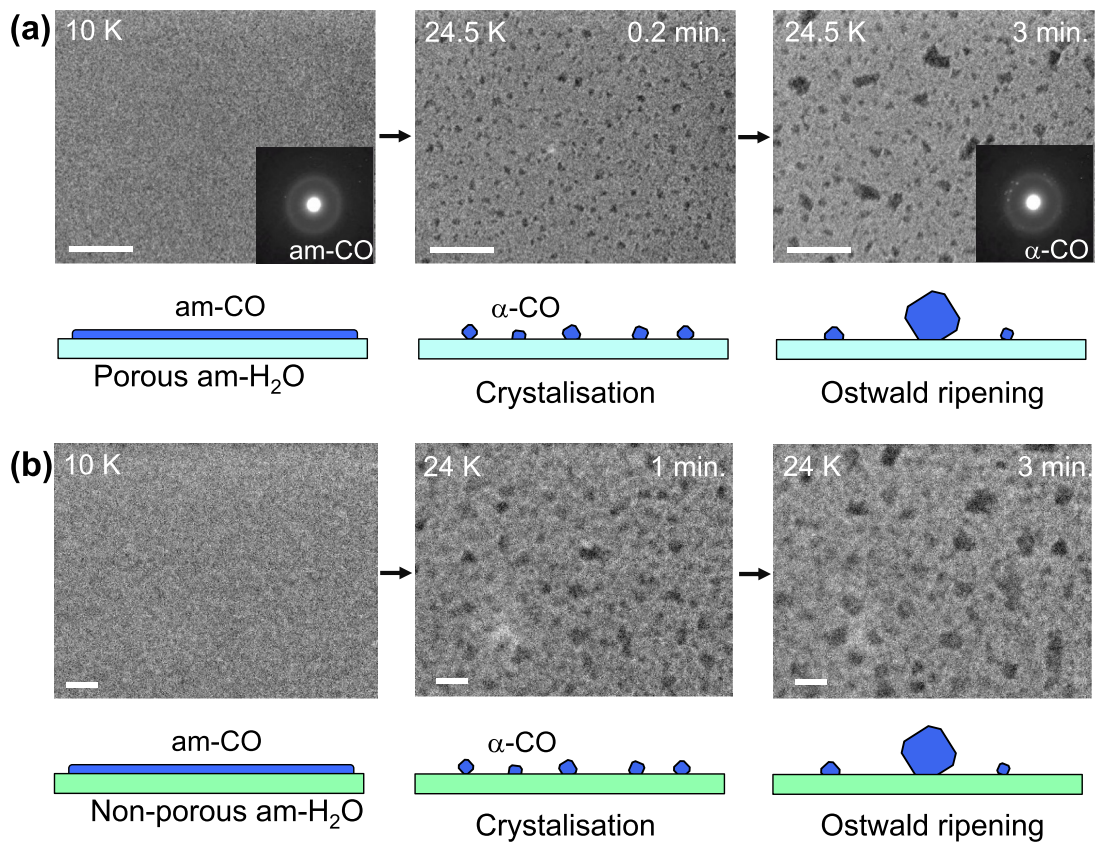

Figure 5. In situ TEM observations and corresponding schematics of the crystallization of am- $\mathrm{CO}$ at $24.5 \mathrm{~K}$ deposited on porous am- $\mathrm{H}_{2} \mathrm{O}$ (a) and that at $24 \mathrm{~K}$ on non-porous am- $\mathrm{H}_{2} \mathrm{O}$ (b). The times shown were noted after heating to $24.5 \mathrm{~K}$ (a) and $24 \mathrm{~K}$ (b). The corresponding electron diffraction patterns are shown in some images. All scale bars are $500 \mathrm{~nm}$.

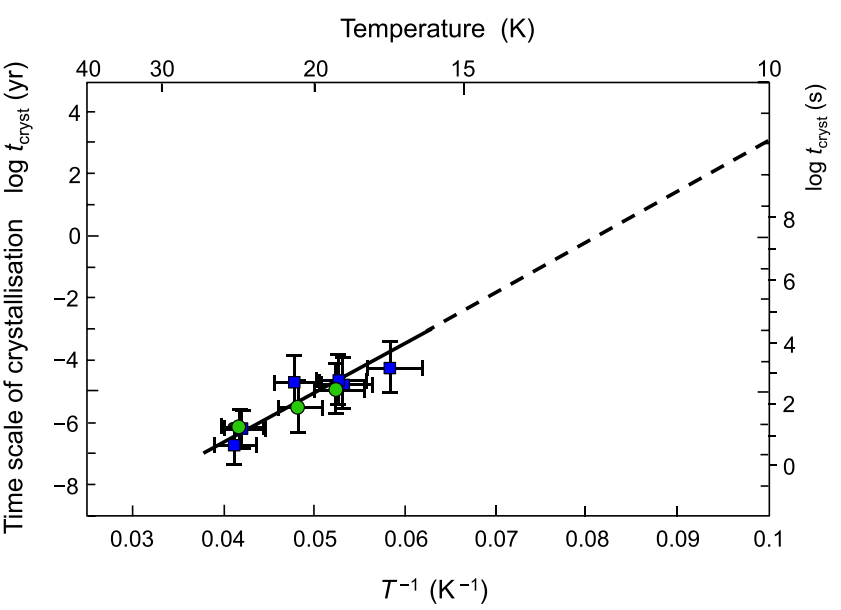

Figure 6. Time-scales of 100 per cent crystallization of am-CO $\left(t_{\text {cryst }}\right)$ on porous am- $\mathrm{H}_{2} \mathrm{O}$ (blue squares) and non-porous am- $\mathrm{H}_{2} \mathrm{O}$ (green circles). The solid line is fitting by equation (1), and the broken line extrapolation to lower temperatures.

due to surface energy and is termed Ostwald ripening. Note that the size of $\alpha-\mathrm{CO}$ was almost the same as the ice grains observed in interstellar molecular clouds. 3D islands were also formed when am-CO crystallized to form $\alpha-\mathrm{CO}$ on am- $\mathrm{H}_{2} \mathrm{O}$ (Fig. 5). The results in Fig. 5 indicated again that $\alpha$-CO formed by the crystallization of am-CO hardly wets am- $\mathrm{H}_{2} \mathrm{O}$ regardless of the porosity of am- $\mathrm{H}_{2} \mathrm{O}$.

Fig. 6 shows variations in the time-scale of am-CO crystallization, $t_{\text {cryst }}$, with relevance to temperature. We found that there is no difference between $t_{\text {cryst }}$ on porous am- $\mathrm{H}_{2} \mathrm{O}$ (blue squares) and nonporous am- $\mathrm{H}_{2} \mathrm{O}$ (green circles), although $t_{\text {cryst }}$ might have errors of approximately one order of magnitude. This suggests that the nucleation of $\alpha-\mathrm{CO}$ was hardly affected by the porosity of am- $\mathrm{H}_{2} \mathrm{O}$.

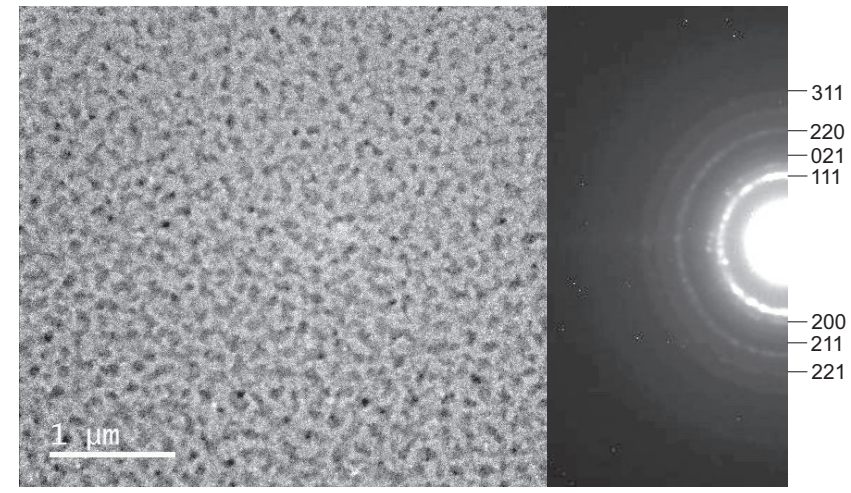

Figure 7. TEM image and the corresponding electron diffraction pattern of a crystalline CO formed via annealing of am-CO on am-Si at $19 \mathrm{~K}$. The electron diffraction pattern confirms that the crystalline $\mathrm{CO}$ is $\alpha-\mathrm{CO}$.

Therefore, $t_{\text {cryst }}$ was fitted following Kouchi et al. (1994) by

$t_{\text {cryst }}=A \exp (E / k T)$,

where $A$ and $E$ are constants determined from the fitting, $k$ is Boltzmann's constant, and $T$ represents the temperature. We obtained $A=1.4 \times 10^{-6} \mathrm{~s}$ and $E / k=375 \mathrm{~K}$.

\subsection{Structure of crystalline $\mathrm{CO}$}

We analysed the electron diffraction pattern obtained from the crystallization of am-CO on am-Si at $19 \mathrm{~K}$ (Fig. 7). This sample is suitable for analysis because there are many diffraction spots from many tiny crystals, the so-called Debye-Scherrer rings. We identified from seven Debye-Scherrer rings that this sample is $\alpha$-CO. Furthermore, it was confirmed that all the diffraction spots observed in Figs 3 and 5 belong to some diffractions shown in Fig. 7. As the 

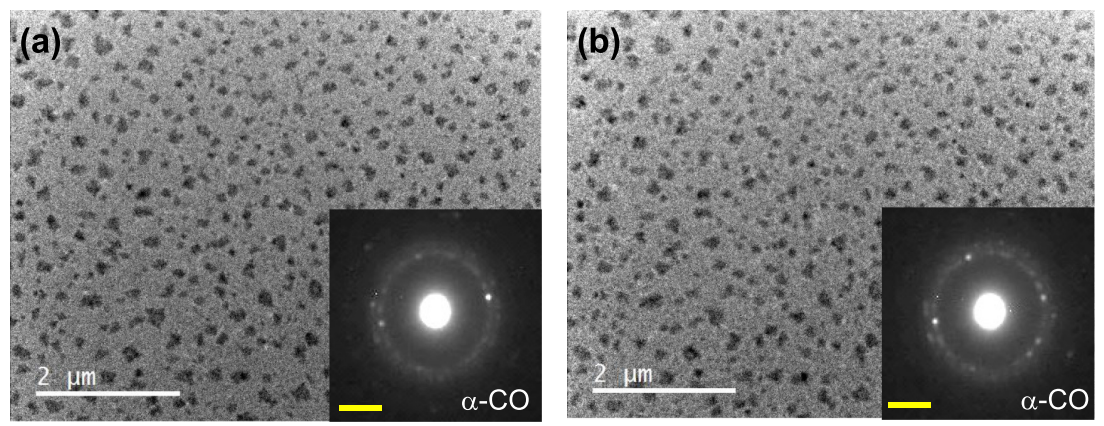

Figure 8. TEM observation of UV irradiation experiment: (a) $\alpha$-CO deposited on am-Si film at $19 \mathrm{~K}$, (b) 30-min UV-irradiated $\alpha$-CO at $10 \mathrm{~K}$. The corresponding electron diffraction patterns are attached to respective TEM images (all yellow bars are $2 \mathrm{~nm}^{-1}$ ). A 30 -min UV irradiation period corresponds to $4 \times 10^{5} \mathrm{yr}$ of UV irradiation in the molecular clouds, if we assume that the UV flux in molecular clouds is $10^{3}$ photons $\mathrm{cm}^{-2} \mathrm{~s}^{-1}$.

formation conditions of crystalline $\mathrm{CO}$ observed in Figs 3 and 5 are similar with that in Fig. 7, those crystals could also be $\alpha$-CO.

\subsection{Effect of UV rays and electron beam irradiation on the $\alpha-\mathbf{C O}$}

Although the above results indicated the presence of $\alpha$-CO instead of am-CO in space, there was a possibility that $\alpha$-CO might be amorphized under UV irradiation or cosmic ray bombardment. Therefore, we performed UV and strong electron beam irradiation experiments at $10 \mathrm{~K}$. After a 30-min UV irradiation, which corresponded to a timescale of $\sim 4 \times 10^{5} \mathrm{yr}$ in the molecular clouds, we did not observe any textural and structural changes in the crystals (Fig. 8), indicating that the $\alpha$-CO crystal was not amorphized via UV exposure. The strong electron beam irradiation experiment also revealed that $\alpha$ CO sputtering proceeded preferentially over amorphization (Fig. 9). Tsuge et al. (2020) observed the similar phenomena that crystalline $\mathrm{CO}_{2}$ was not amorphized by the irradiation of UV rays or strong electron beam.

Urso et al. (2016) did not observe any changes in the IR and Raman band at $2140 \mathrm{~cm}^{-1}$, which was associated with solid CO, after bombardment with $200 \mathrm{keV} \mathrm{H}^{+}$. Although there was no discussion about the crystallinity of their samples, we speculate that the samples from Urso's study were $\alpha$-CO because the reported deposition temperature was rather high at $17 \mathrm{~K}$ and there was no reported change in the $2140 \mathrm{~cm}^{-1}$ band between 17 and $32 \mathrm{~K}$. Thus, it was reasonable to interpret their results as evidence of no $\alpha$-CO amorphization at $17 \mathrm{~K}$. Therefore, we conclude that $\alpha-\mathrm{CO}$ are never amorphized by the UV irradiation or cosmic ray bombardment at low temperatures.

\subsection{UV and electron beam-induced crystallization of am-CO}

In am- $\mathrm{CO}_{2}$, Tsuge et al. (2020) observed that am- $\mathrm{CO}_{2}$ was crystallized by the irradiation of UV rays or strong electron beam. To clarify this possibility in am-CO, we performed UV and strong electron beam irradiation experiments at $10 \mathrm{~K}$. After a 10-min UV irradiation, which corresponded to a time-scale of $1.3 \times 10^{5} \mathrm{yr}$ in the molecular clouds, formation of $\alpha$-CO was observed (Fig. 10). The strong electron beam irradiation experiment revealed that sputtering of am-CO proceeded preferentially (Fig. 11a). Simultaneously, crystallization of am-CO proceeded rapidly only in electron beamirradiated region (Fig. 11c) but did not on the non-irradiated region (Fig. 11b). Here, we conclude that irradiation preferentially promoted am-CO crystallization, and from the results of Sections 3.4 and 3.5, there is no am-CO in molecular clouds.
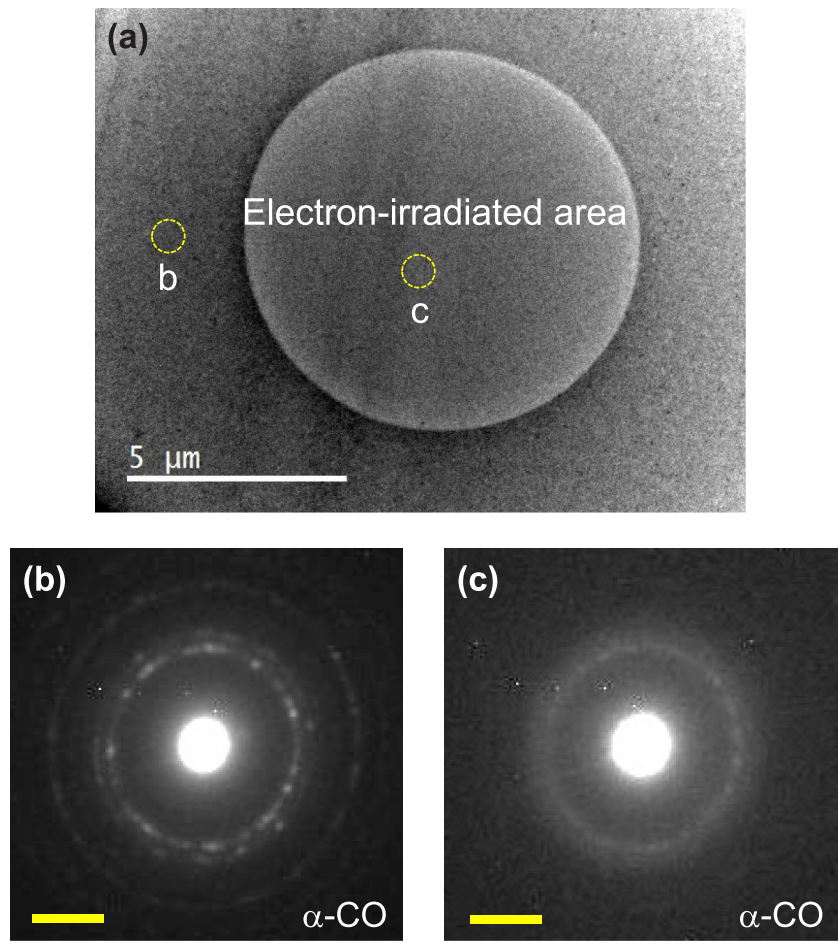

Figure 9. Low-magnification TEM image (a), the electron diffraction patterns of the non-irradiated position (b), and the irradiated position (c) after $\alpha-\mathrm{CO}$ was exposed to $80-\mathrm{kV}$ electron beam irradiation for $5 \mathrm{~min}$ at $10 \mathrm{~K}$. The flux of the electron beam during irradiation was $\sim 1$ electrons $\AA^{-2} \mathrm{~s}^{-1}$. Although most of the $\alpha$-CO was sputtered, the electron diffraction pattern (c) clearly showed that the remaining $\mathrm{CO}$ was crystalline $(\alpha-\mathrm{CO})$. The sputtering rate of $\alpha$-CO was roughly estimated as $\sim 4 \mathrm{~nm} \mathrm{~min}{ }^{-1}$, which corresponded to a sputtering yield of $\sim 0.2$ molecules electron ${ }^{-1}$. The scale bars in electron diffraction patterns are $2 \mathrm{~nm}^{-1}$.

\section{DISCUSSION}

\subsection{Surface diffusion coefficients of CO}

Although the value of surface diffusion coefficient of $\mathrm{CO}$ on am- $\mathrm{H}_{2} \mathrm{O}$, $D_{\mathrm{s}}$, is necessary to discuss various phenomena, there was no direct means of measuring it. Therefore, we calculated $D_{\mathrm{s}}$ using the $E_{\mathrm{sd}}(350$ $\pm 50 \mathrm{~K}$ ) value on porous am- $\mathrm{H}_{2} \mathrm{O}$ measured by Kouchi et al. (2020) and that on non-porous am- $\mathrm{H}_{2} \mathrm{O}$ measured herein $(200 \pm 40 \mathrm{~K})$. Assuming that the pre-exponential factor, $D_{0}$, is expressed by $b^{2} v$ $\left(v=10^{12} \mathrm{~s}^{-1}\right.$ ), where $v$ is the hopping frequency of the adsorbed 

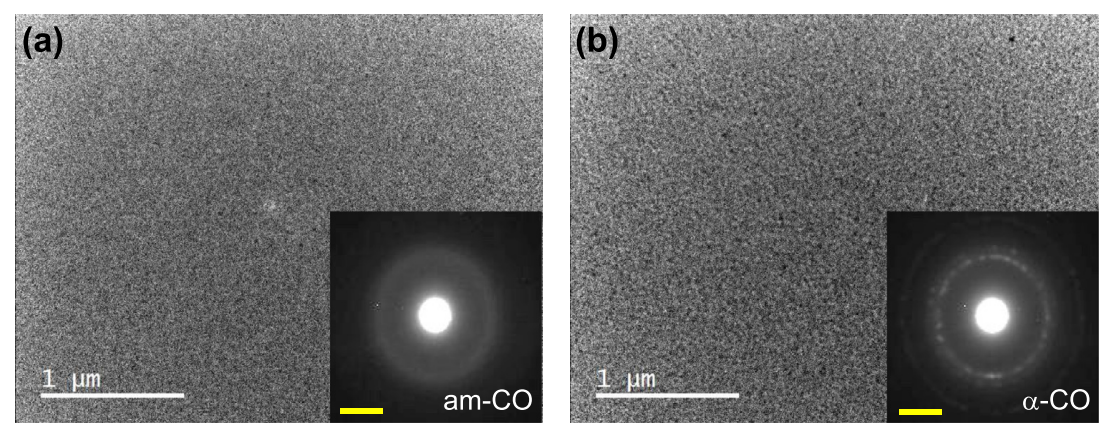

Figure 10. TEM observation of the UV irradiation experiments for am-CO deposited on am-Si film at $10 \mathrm{~K}$ (a) and $\alpha$-CO after 10 -min UV irradiation at $10 \mathrm{~K}$ (b). The corresponding electron diffraction patterns are attached to the respective TEM images (all yellow bars are $2 \mathrm{~nm}^{-1}$ ). A 10-min UV irradiation period corresponds to $1.3 \times 10^{5} \mathrm{yr}$ of UV irradiation in the molecular clouds.
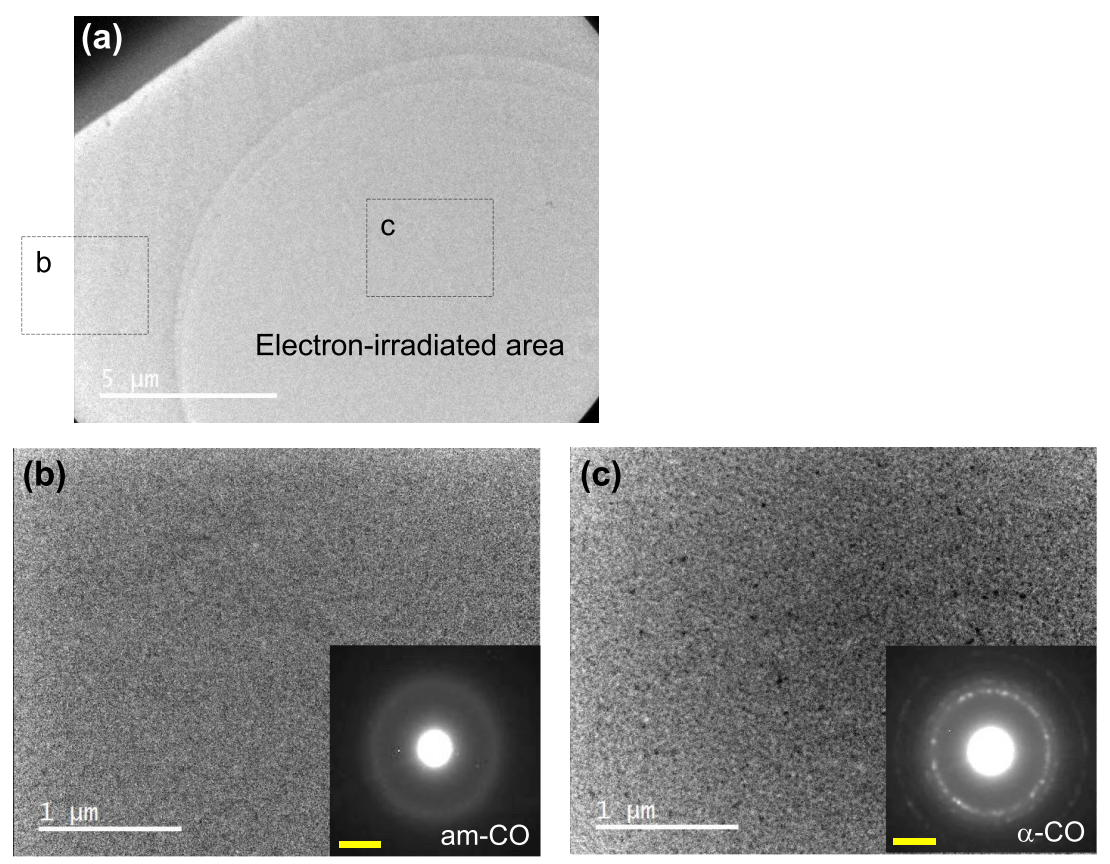

Figure 11. TEM observation of electron beam irradiation of am-CO after $15 \mathrm{~min}$ at $10 \mathrm{~K}$. Low-magnification TEM image (a), and high-magnification images of the non-irradiated (b) and irradiated regions (c), respectively. The flux of the electron beam during irradiation was $\sim 0.4$ electrons $\AA^{-2} \mathrm{~s}^{-1}$. The scale bars in the electron diffraction patterns are $2 \mathrm{~nm}^{-1}$.

$\mathrm{CO}$ molecules, $b$ the distance to the neighbouring adsorption site. This assumption was plausible because the error of $v$ was one order of magnitude (Hama \& Watanabe 2013). The calculated $D_{\text {s }}$ of $\mathrm{CO}$ on am- $\mathrm{H}_{2} \mathrm{O}$ (Fig. 12) revealed that the $\mathrm{CO}$ molecules diffuse almost freely on porous and non-porous am- $\mathrm{H}_{2} \mathrm{O}$ even at $10 \mathrm{~K}$.

It is well known that am- $\mathrm{H}_{2} \mathrm{O}$ made by the vapour deposition at $10 \mathrm{~K}$ is extremely porous, the porosity decreases with temperature, and am- $\mathrm{H}_{2} \mathrm{O}$ became non-porous at temperatures higher than $90 \mathrm{~K}$ (e.g. Stevenson et al. 1999). While, Palumbo (2006) and Accolla et al. (2011) observed that porous am- $\mathrm{H}_{2} \mathrm{O}$ changed to non-porous am- $\mathrm{H}_{2} \mathrm{O}$ at low temperatures by irradiation of high-energy ion and $\mathrm{H}$ atoms, respectively, Oba et al. (2009) showed experimentally that am$\mathrm{H}_{2} \mathrm{O}$ formed by the surface atomic reactions at $10-40 \mathrm{~K}$ is compact and non-porous. At present, it is difficult to assess which is suitable for mimicking am- $\mathrm{H}_{2} \mathrm{O}$ in molecular clouds, porous or non-porous am- $\mathrm{H}_{2} \mathrm{O}$. It is noted that this ambiguity does not affect the following discussion because we use $E_{\mathrm{sd}}=350 \mathrm{~K}$ in Section 4.3.

\subsection{Wetting of $\mathrm{CO}$ against am- $\mathrm{H}_{2} \mathrm{O}$}

Before discussing the wetting of $\mathrm{CO}$ against am- $\mathrm{H}_{2} \mathrm{O}$, which is an important factor controlling the morphology of icy interstellar grains, we will briefly review growth modes of thin film on the substrate. Fig. 13(a)-(c) schematically illustrates three modes of thin film growth (e.g Smith 1995, chapters 5 and 6). The crystal grows as an uniform film or wets the substrate completely as shown in Fig. 13(a) because

$\gamma_{\mathrm{c}}+\gamma_{\mathrm{i}}<\gamma_{\mathrm{s}}$

where $\gamma_{\mathrm{c}}$ and $\gamma_{\mathrm{s}}$ are surface energies of crystal and substrate, respectively, and $\gamma_{\mathrm{i}}$ interfacial energy between crystal and substrate. This suggests that total surface energy decreases for the wetted substrate than that for the bare one. This growth mode is referred to as the Frank-van der Merwe growth. When $\gamma_{\mathrm{s}}$ becomes smaller,

$\gamma_{\mathrm{c}}+\gamma_{\mathrm{i}}>\gamma_{\mathrm{s}}$ 


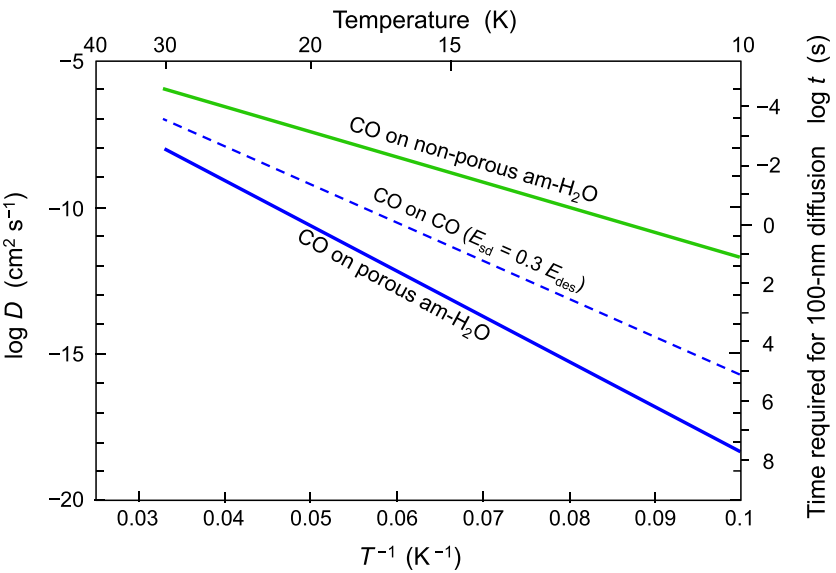

Figure 12. Surface diffusion coefficients of $\mathrm{CO}$ on porous am- $\mathrm{H}_{2} \mathrm{O}$ (blue solid line) and non-porous am- $\mathrm{H}_{2} \mathrm{O}$ (green solid line) and $\mathrm{CO}$ on $\alpha$-CO (broken line). The time required for 100-nm diffusion on the 2D substrate is also shown in the right ordinate.

the film does not wet the substrate but forms 3D islands, as shown in Fig. 13(b). This growth mode is referred to as the Volmer-Weber growth. Third growth mode is referred to as the Stranski-Krastanov in which the growth changes from layer to islands due to the change of energy situation as follows:

$\gamma_{\mathrm{c}}+\gamma_{\mathrm{c}^{\prime}}+U>\gamma_{\mathrm{c}^{\prime \prime}}$

where $\gamma_{\mathrm{c}^{\prime \prime}}$ is surface energy of monolayer-covered substrate and $\gamma_{\mathrm{c}^{\prime}}$ interfacial energy between crystal and monolayer-covered substrate. $U$ is strain energy term mainly owing to the lattice mismatch. When $U$ becomes sufficiently large such that the inequality (2) is not satisfied, growth mode changes from film growth to 3D island growth, as shown in Fig. 13(c).

In $\mathrm{CO}$ deposition on non-porous am- $\mathrm{H}_{2} \mathrm{O}$, we did not observe complete wetting but partial wetting, as in Figs 2(b) and 3. Conversely, Noble et al. (2012), via a temperature-programmed desorption method, observed that $\mathrm{CO}$ adsorbed the whole surface of non-porous am- $\mathrm{H}_{2} \mathrm{O}$, complete wetting, as schematically shown in Fig. 13(d). We will discuss on these experimental results. In the latter case, following inequality should be satisfied,

$\gamma_{\mathrm{CO}}+\gamma_{\mathrm{H} 2 \mathrm{O}-\mathrm{CO}}<\gamma_{\mathrm{H} 2 \mathrm{O}}$,

where $\gamma_{\mathrm{CO}}$ and $\gamma_{\mathrm{H} 2 \mathrm{O}}$ are surface energies of $\mathrm{CO}$ and $\mathrm{am}-\mathrm{H}_{2} \mathrm{O}$ substrate, respectively, and $\gamma_{\mathrm{H} 2 \mathrm{O}-\mathrm{CO}}$ interfacial energy between $\mathrm{CO}$ and am- $\mathrm{H}_{2} \mathrm{O}$ substrate. In these systems, there has been no direct measurement of surface energy and interface energy. However, we could check inequality (equation 5) using measured binding energies because surface energy $\gamma$ is expressed by $\gamma \sim E / d^{2}$, where $E$ is binding energy and $d$ lattice constant for crystal. If we assume that $d$ is constant regardless of materials and crystallinity, inequality (equation 5) could be rewritten to

$E_{\mathrm{CO}}+E_{\mathrm{CO}-\mathrm{H} 2 \mathrm{O}}<E_{\mathrm{H} 2 \mathrm{O}}$,

where $E_{\mathrm{CO}}, E_{\mathrm{H} 2 \mathrm{O}}$, and $E_{\mathrm{CO}-\mathrm{H} 2 \mathrm{O}}$ are binding energies of $\mathrm{CO}$ on solid $\mathrm{CO}, \mathrm{H}_{2} \mathrm{O}$ on non-porous am- $\mathrm{H}_{2} \mathrm{O}$, and $\mathrm{CO}$ on non-porous am- $\mathrm{H}_{2} \mathrm{O}$, respectively. If we use $E_{\mathrm{CO}}=960 \mathrm{~K}$ (Sandford \& Allamandola 1988), $E_{\mathrm{CO}-\mathrm{H} 2 \mathrm{O}}=830 \mathrm{~K}$ (Noble et al. 2012), and $E_{\mathrm{H} 2 \mathrm{O}}=5070 \mathrm{~K}$ (Sandford \& Allamandola 1988), it is clear that inequality (equation 6) and thus inequality (equation 5) hold, supporting conclusion of Noble et al. on complete wetting. It is noted that the observation of adsorption layer using TEM is extremely difficult. Conversely, the detection by temperature-programmed desorption method (e.g. Noble et al. 2012; Fayolle et al. 2016) or infrared spectroscopy (e.g. Collings et al. 2003) is not so difficult. Kouchi (1990) obtained reflection electron diffraction pattern of adsorbed $\mathrm{CO}$ on am- $\mathrm{H}_{2} \mathrm{O}$ using the reflection high-energy electron diffraction and found that adsorbed $\mathrm{CO}$ was not crystalline but amorphous-like. In addition, the fact that inequalites (equation 5) and (equation 6) hold also suggests that the Volmer-Weber mode growth shown in Fig. 13(e) does not proceed.

Once the surface of non-porous am- $\mathrm{H}_{2} \mathrm{O}$ has been covered completely by adsorbed $\mathrm{CO}$ as shown in Fig. 13(d), energy situation has been changed from Figs 13(e) to (f). As a result, growth mode of $\mathrm{CO}$ should be changed from thin film mode ( $\mathrm{CO}$ adsorption) to island growth like the Stranski-Krastanov mode (Fig. 13c). In this case, following inequalities should hold:

$$
\begin{aligned}
& \gamma_{\mathrm{CO}}+\gamma_{\mathrm{COads}-\mathrm{COcryst}}+U^{\prime}>\gamma_{\mathrm{COads}} \\
& E_{\mathrm{CO}}+E_{\mathrm{COads}-\mathrm{COcryst}}+E^{\prime}>E_{\mathrm{COads}},
\end{aligned}
$$

(a) Frank-van der Merwe

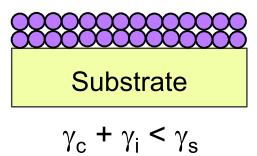

(d) Adsorption

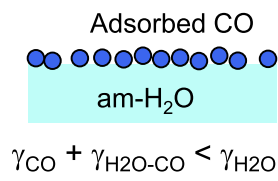

(b) Volmer-Weber

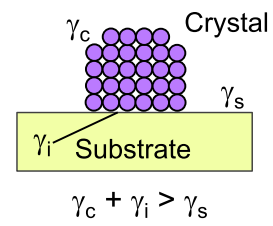

(e) Volmer-Weber

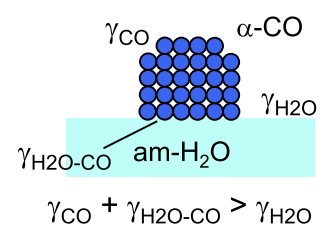

(c) Stranski-Krastanov

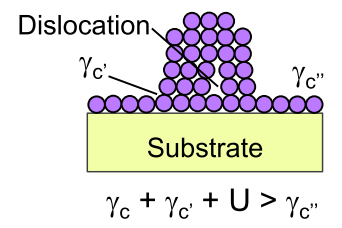

(f) Modified Stranski-Krastanov

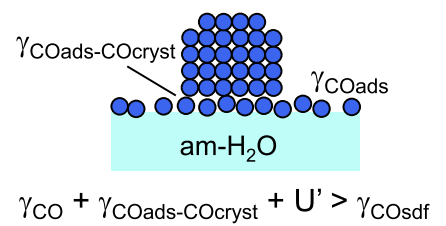

Figure 13. Schematic illustrations of thin film growth on the crystalline substrate (a-c) and $\mathrm{CO}$ adsorption and growth on the am- $\mathrm{H}_{2} \mathrm{O}$ substrate $(\mathrm{d}-\mathrm{f})$. Corresponding relations on surface and interfacial energies are also shown. 


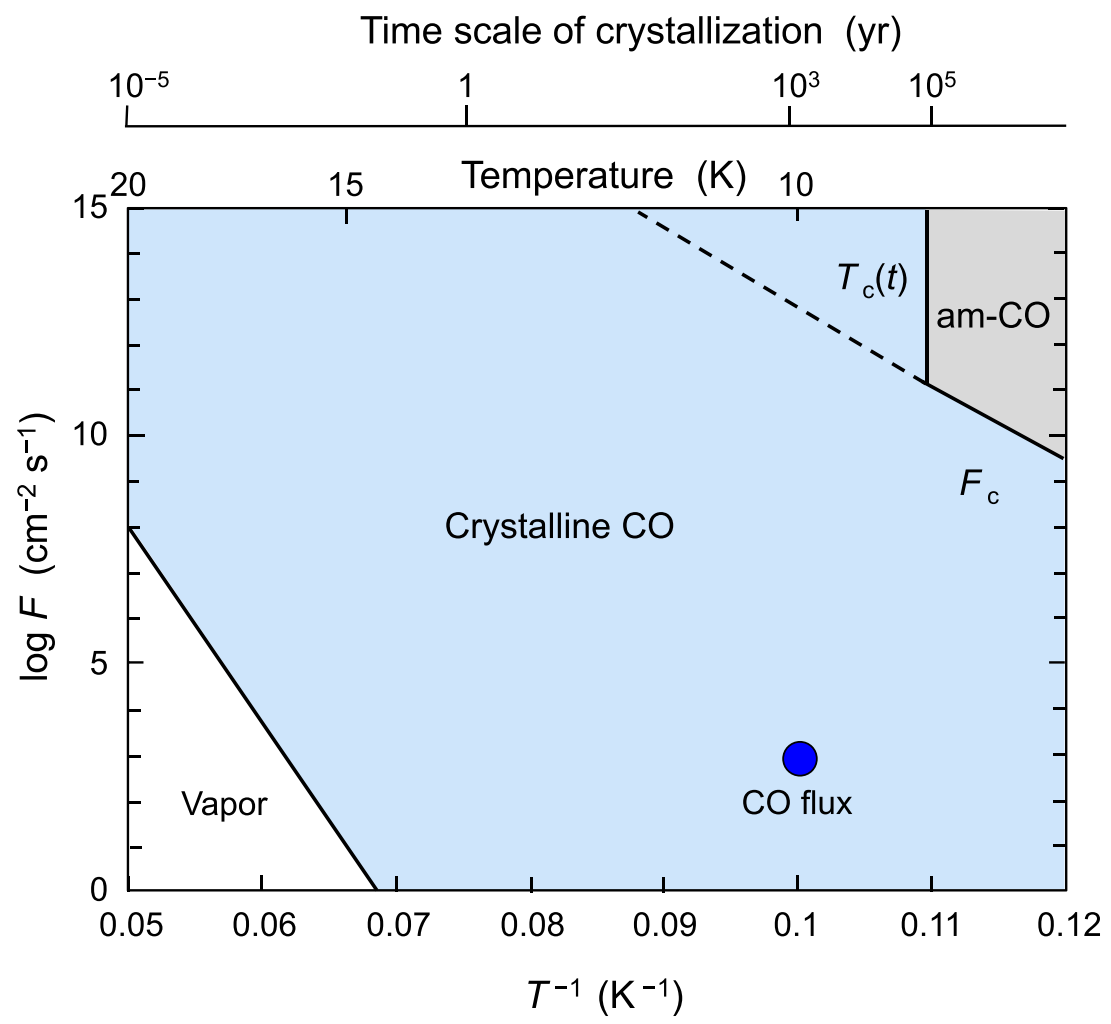

Figure 14. The crystallinity of solid $\mathrm{CO}$ in molecular clouds. $F_{\mathrm{c}}$ is the critical flux above which the am-CO is deposited, and $T_{\mathrm{c}}(t)$ is the crystallization temperature threshold of am-CO as a function of the time-scale $\left(t_{\text {cryst }}\right)$. The time-scale for crystallization is shown in the upper abscissa. Thus, the $F-T$ condition for am-CO is limited only to grey region. Conversely, the $\mathrm{CO}$ crystallization becomes wide within the $F-T$ ranges, as shown in pale-blue. The CO flux in the molecular clouds is shown by a blue circle.

where $\gamma_{\text {COads }}$ is surface energy of CO-adsorbed non-porous am- $\mathrm{H}_{2} \mathrm{O}$, $\gamma_{\text {COads-COcryst }}$ interfacial energy between $\mathrm{CO}$-adsorbed non-porous am- $\mathrm{H}_{2} \mathrm{O}$, and $\alpha$-CO, $U^{\prime}$ extra energy due to misfit between $\mathrm{CO}$ adsorbed non-porous am- $\mathrm{H}_{2} \mathrm{O}$ and $\alpha$-CO, $E_{\text {COads }}$, and $E_{\text {COads-COcryst }}$ binding energies of $\mathrm{CO}$ on $\mathrm{CO}$-adsorbed non-porous am- $\mathrm{H}_{2} \mathrm{O}$ and that between $\alpha-\mathrm{CO}$ and $\mathrm{CO}$-adsorbed layer, respectively, and $E^{\prime}$ is defined by $U^{\prime} \sim E^{\prime} / d^{2}$. If we assume that $E_{\text {COads }}$ and $E_{\text {COads-COcryst }}$ have similar values to $E_{\mathrm{CO}}$, it is clear that inequality (equation 7) and thus inequality (equation 8) hold. Above discussion clearly explains both observations of Noble et al. and ours on $\mathrm{CO}$ deposition process on non-porous am- $\mathrm{H}_{2} \mathrm{O}$. Furthermore, it is suggested that the small value of the $E_{\mathrm{sd}}$ on non-porous am- $\mathrm{H}_{2} \mathrm{O}$ measured herein $(200 \pm 40 \mathrm{~K})$ might be attributed to the complete wetting of $\mathrm{CO}$ on non-porous am- $\mathrm{H}_{2} \mathrm{O}$.

In $\mathrm{CO}$ deposition on porous am- $\mathrm{H}_{2} \mathrm{O}$, Kouchi et al. (2020) attributed the formation of 3D islands of $\alpha$-CO to a bad wetting, shown as schematics in Fig. 2(a). However, our observation cannot reveal whether the surface of porous am- $\mathrm{H}_{2} \mathrm{O}$ is covered by adsorbed $\mathrm{CO}$ (i.e. Figs $13 \mathrm{f}$ or e, respectively). There has been no quantitative analysis of the $\mathrm{CO}$ adsorption on porous am- $\mathrm{H}_{2} \mathrm{O}$ like Noble et al. (2012), wherein complete wetting of $\mathrm{CO}$ on non-porous am- $\mathrm{H}_{2} \mathrm{O}$ was reported. Therefore, it is highly desirable to perform quantitative analysis of the $\mathrm{CO}$ adsorption on porous am- $\mathrm{H}_{2} \mathrm{O}$ from the point of view of wetting.

\subsection{Crystallinity of solid CO in molecular clouds}

The crystallinity of solid CO in molecular clouds could be discussed by considering the flux of $\mathrm{CO}$ molecules and the time-scale of crystallization of am-CO, as demonstrated in $\mathrm{H}_{2} \mathrm{O}$ ice (Kouchi et al. 1994).

Here, the condition for the formation of am-CO during vapour deposition was expressed by:

$F>F_{\mathrm{c}} \equiv D_{\mathrm{s}} / a^{4}=D_{0} \exp \left(-E_{\mathrm{sd}} / k T\right) / a^{4}$,

where $F$ is a flux of $\mathrm{CO}$ vapour, $F_{\mathrm{c}}$ is the critical flux, $D_{\mathrm{s}}$ is the surface diffusion coefficient of $\mathrm{CO}$ on $\mathrm{am}-\mathrm{H}_{2} \mathrm{O}$, $a$ represents the distance to the neighbouring $\mathrm{CO}$ molecules on the surface of the CO crystal $(a=0.3 \mathrm{~nm}), D_{0}$ is the pre-exponential factor, $E_{\mathrm{sd}}$ is the activation energy of surface diffusion, $k$ is Boltzmann's constant, and $T$ represents the temperature (Kouchi et al. 1994).

The CO flux in 10-K molecular clouds was calculated following Kouchi et al. (1994), where the density of $\mathrm{H}_{2}$ was assumed to be $10^{4}$ $\mathrm{cm}^{-3}$ and the abundance ratio of $\mathrm{CO} / \mathrm{H}_{2}$ was $10^{-4}$; the value was determined to be $\sim 10^{3}$ molecules $\mathrm{cm}^{-2} \mathrm{~s}^{-1}$. As shown in Fig. 14, the critical flux $\left(F_{\mathrm{c}}\right)$ calculated using equation (9) was 10 orders of magnitude larger than the $\mathrm{CO}$ flux. Although above discussion strictly holds only for the crystalline $\mathrm{CO}$ substrate, experimental results shown in Fig. 3 suggest that the above discussion also holds on the am- $\mathrm{H}_{2} \mathrm{O}$. Taking the above discussion and experimental results shown in Fig. 3 into consideration, we conclude that the solid CO deposited in molecular clouds was crystalline $(\alpha-\mathrm{CO})$.

The condition required for preserving am-CO was determined by the crystallization time-scale $\left(t_{\text {cryst }}\right)$ of am-CO in Fig. 6 . If the fitting of equation (1) was extrapolated to the lower temperatures as shown by broken line, the time-scale of crystallization was estimated to be $10^{3} \mathrm{yr}$ at $10 \mathrm{~K}$. From these data, we could obtain the temperature of crystallization $\left[T_{\mathrm{c}}\left(t_{\text {cryst }}\right)\right]$, which was defined by the temperature 


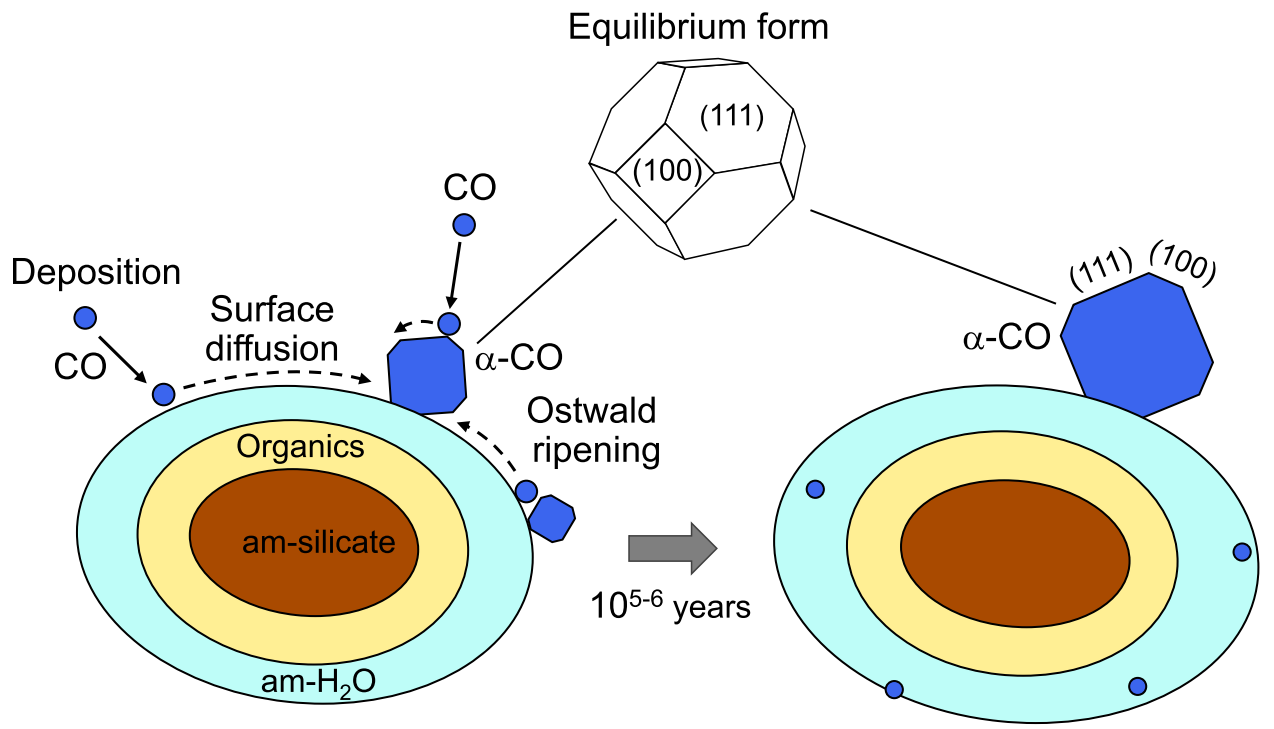

Figure 15. Schematic of the formation and evolution of a CO crystal on the ice grain in molecular clouds.

above which crystallization occurred on the time-scale $\left(t_{\text {cryst }}\right)$. For example, $T_{\mathrm{c}}\left(10^{5} \mathrm{yr}\right)$ was $9 \mathrm{~K}$, as shown in Fig. 14. This clearly showed that even if am-CO was formed, the am-CO crystallized on a time-scale much shorter than the deposition time-scale of $10^{5-6} \mathrm{yr}$. This also supported the above-mentioned conclusion that the solid $\mathrm{CO}$ in molecular clouds was crystalline $(\alpha-\mathrm{CO})$.

In the above discussion, we did not consider the effect of $\mathrm{H}_{2} \mathrm{O}$ molecules formed simultaneously. To clarify the effect of $\mathrm{H}_{2} \mathrm{O}$, we should compare the time-scale for $\mathrm{CO}$ diffusion on $\mathrm{am}-\mathrm{H}_{2} \mathrm{O}$ with the coverage time-scale by $\mathrm{H}_{2} \mathrm{O}$. The coverage time-scale by $\mathrm{H}_{2} \mathrm{O}$ molecules, $t_{\text {cover }}$, is given by (10)

$t_{\text {cover }}=1 / F_{\mathrm{H} 2 \mathrm{O}} a^{2}$,

where $F_{\mathrm{H} 2 \mathrm{O}}$ is the hypothetical flux of $\mathrm{H}_{2} \mathrm{O}$ onto the surface. As the formation of $\mathrm{H}_{2} \mathrm{O}$ molecules occurs via surface atomic reactions including O-atoms (Miyauchi et al. 2008; Ioppolo et al. 2008; Dulieu et al. 2010; Oba et al. 2012; Hama \& Watanabe 2013), it could be assumed that $F_{\mathrm{H} 2 \mathrm{O}} \sim F_{\mathrm{O}}$, where $F_{\mathrm{O}}$ is the flux of O-atoms. Kouchi et al. (1994) estimated the $F_{\mathrm{O}}$ in $10-\mathrm{K}$ molecular clouds to be $2.7 \times 10^{3}$ atoms cm $\mathrm{cm}^{-2} \mathrm{~s}^{-1}$. Then $t_{\text {cover }}$ is calculated to be $4 \times 10^{11} \mathrm{~s}$, which is significantly longer than the time required for the $100-\mathrm{nm}$ $\mathrm{CO}$ diffusion on am- $\mathrm{H}_{2} \mathrm{O}, \sim 10^{8}$ s (see Fig. 12). This result clearly shows that most $\mathrm{CO}$ was not buried in am- $\mathrm{H}_{2} \mathrm{O}$ but diffused on am$\mathrm{H}_{2} \mathrm{O}$ to form a few $\alpha$-CO and that the above discussion ignoring the effect of $\mathrm{H}_{2} \mathrm{O}$ was not invalid.

When all the experimental results and above discussions were taken into consideration, we concluded that molecular clouds contained crystalline $\mathrm{CO}(\alpha-\mathrm{CO})$ but no am-CO. This was supported by reports detailing the absence of amorphous $\mathrm{CO}_{2}$ in molecular clouds (Escribano et al. 2013; Tsuge et al. 2020) due to the considerably lower am-CO crystallization temperature relative to its am- $\mathrm{CO}_{2}$ counterpart.

\subsection{Formation of $\alpha$-CO in molecular clouds}

Information on the surface diffusion coefficient is essential for identifying $\alpha-\mathrm{CO}$ and determining its morphology on the am- $\mathrm{H}_{2} \mathrm{O}$ grain. As already shown, $\mathrm{CO}$ molecules diffused almost freely on am- $\mathrm{H}_{2} \mathrm{O}$ even in $10 \mathrm{~K}$. Since there was no direct means of measuring the surface self-diffusion coefficients of $\mathrm{CO}$ on $\alpha$-CO, we calculated this value shown by the broken line in Fig. 12, assuming that the activation energy of the surface diffusion was 0.3 of that of the desorption (Sandford \& Allamandola 1988). This, too, was evidence that the $\mathrm{CO}$ molecules diffused almost freely on $\alpha-\mathrm{CO}$ even at $10 \mathrm{~K}$.

These results implied that there should be only one $\alpha-\mathrm{CO}$ on each am- $\mathrm{H}_{2} \mathrm{O}$ ice grain in molecular clouds and that $\alpha$-CO should be its equilibrium form. Generally, the equilibrium form of crystal is defined as the prevailing crystal form when thermodynamic equilibrium is attained. In this case, the Gibbs free energy of the system, which is the sum of the volume and surface energies, should be minimized. Report has shown that the equilibrium form of the $\alpha$-CO might be a truncated-regular octahedron (Toschev 1973).

From the findings of this study, we proposed a mechanism for the formation of ice on the refractory grains in molecular clouds. The general tendency of the compositional changes of the ice, which was detailed using various chemical evolution models (Garrod \& Pauly 2011; Furuya et al. 2015; Ruaud et al. 2016; Kouchi et al. 2020), consisted of the inner portion comprising pure $\mathrm{H}_{2} \mathrm{O}$ linked to the $\mathrm{H}_{2} \mathrm{O}: \mathrm{CO}_{2}$ transition layer, followed by the $\mathrm{H}_{2} \mathrm{O}: \mathrm{CO}: \mathrm{CO}_{2}$ outer layer. The $\mathrm{H}_{2} \mathrm{O}$ molecules were formed continuously via surface atomic reactions (Miyauchi et al. 2008; Ioppolo et al. 2008; Dulieu et al. 2010; Oba et al. 2012; Hama \& Watanabe 2013), resulting in the formation of am- $\mathrm{H}_{2} \mathrm{O}$ (Fig. 15). Conversely, the solid $\mathrm{CO}$ was formed via $\mathrm{CO}$ deposition from the vapour phase. The solid $\mathrm{CO}$ deposited was one single $\alpha$-CO crystal because the $\mathrm{CO}$ molecules diffused onto am- $\mathrm{H}_{2} \mathrm{O}$ almost freely thanks to the very large diffusion coefficient (Fig. 12), thereby accumulating to form one crystal. In other words, Ostwald ripening proceeded very efficiently. As already shown, solid $\mathrm{CO}$ should be crystalline, and $\alpha-\mathrm{CO}$ was its projected equilibrium form. Remaining $\mathrm{CO}$ molecules might be adsorbed on am- $\mathrm{H}_{2} \mathrm{O}$ and trapped in am- $\mathrm{H}_{2} \mathrm{O}$ as an impurity. IR observations of $\mathrm{CO}$ ice band $(4.67 \mu \mathrm{m})$ show the occurrence of two major $\mathrm{CO}$ bands: one comprises apolar $\mathrm{CO}$ and another comprises polar $\mathrm{CO}$ (e.g. Boogert et al. 2015). The former is regarded as solid CO, and the latter impurity in am- $\mathrm{H}_{2} \mathrm{O}$ and adsorbed $\mathrm{CO}$ on am- $\mathrm{H}_{2} \mathrm{O}$ (e.g. Pontoppidan et al. 2003). These observations are consistent with our present model. In addition, the adsorbed $\mathrm{CO}$ on am- $\mathrm{H}_{2} \mathrm{O}$ might be 


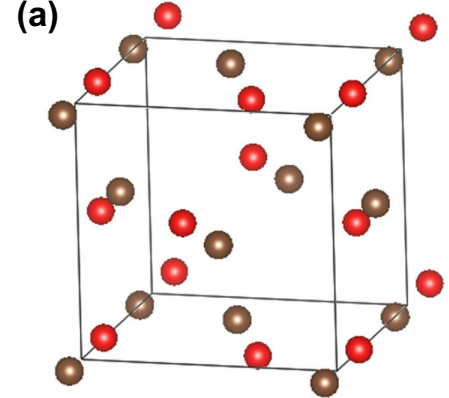

(b)

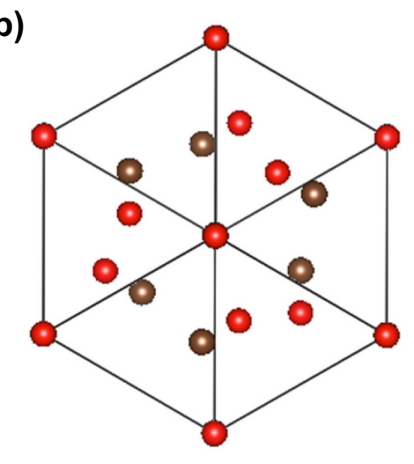

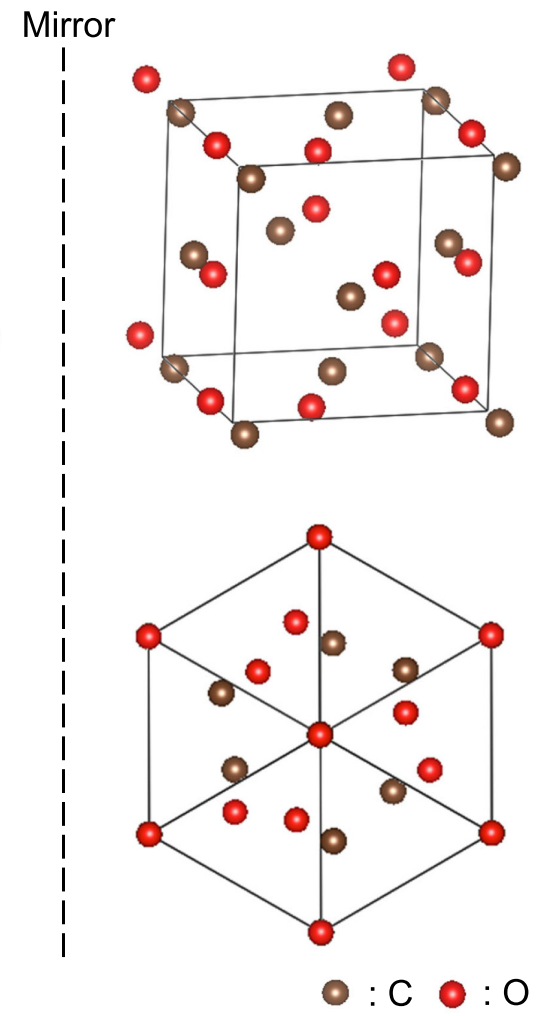

Figure 16. Crystal structure of chiral $\alpha-\mathrm{CO}$ (space group: $P 2{ }_{1} 3$ ). Bird's-eye view (a) and projection form in the $<111>$ direction (b).

reacted with $\mathrm{H}$-atoms or other radicals to form $\mathrm{H}_{2} \mathrm{CO}, \mathrm{CH}_{3} \mathrm{OH}$, and $\mathrm{CO}_{2}$ (e.g. Watanabe \& Kouchi, 2002; Oba et al. 2010). Pontoppidan et al. (2003) and Hama \& Watanabe (2013) suggested the possible presence of $\alpha-\mathrm{CO}$ as apolar $\mathrm{CO}$ towards embedded young low-mass stars. The findings put forward by the present study are in good agreement with the results of Pontoppidan's study. We theorized that because wetting of the $\alpha$-CO crystal against am- $\mathrm{H}_{2} \mathrm{O}$ was bad, as shown in Figs 2 and 5, $\alpha$-CO was not embedded in am- $\mathrm{H}_{2} \mathrm{O}$, as shown in Fig. 15. As a result, the ice grain adopted a morphology similar to that of $\alpha-\mathrm{CO}$, with a truncated-regular octahedron attached to a spherical am- $\mathrm{H}_{2} \mathrm{O}$-covered refractory grain.

\subsection{Is $\alpha$-CO in molecular clouds chiral?}

The crystal structure of $\alpha-\mathrm{CO}$ at low temperatures is cubic, with four $\mathrm{CO}$ molecules in a unit cell and belonged either to the $P 2_{1} 3$ or $P a 3$ space group. The former and the latter are orientationally ordered and disordered phases, respectively. There has been no strong evidence to confirm the structure of $\alpha$-CO via X-ray (Vegard 1930; Mizuno, Kofu \& Yamamuro 2016) or electron diffraction (Kovalenko et al. 1973 ) techniques. This study could not confirm the structure of $\alpha$-CO. Finally, Wang et al. (2020) reported that neutron diffraction studies on $\alpha$-CO at low temperatures confirmed that these crystals belonged to the $P 2_{1} 3$ space group (Fig. 16); thus, $\alpha-\mathrm{CO}$ is chiral, as proposed by Vegard (1930). This was consistent with the results obtained for the heat capacity experiments (Atake, Suga \& Chihara 1976) and the nuclear magnetic resonance and nuclear quadrupole resonance (NMR-NQR) analysis ( $\mathrm{Li}$ et al. 1981). Therefore, we concluded that $\alpha$-CO in molecular clouds belonged to space group $P 2{ }_{1} 3$ and that it was chiral. Chiral crystal occurs in both left- and right-handed variants. These two variants could not be superimposed on each other by any translational and/or rotational operation; however, they could be superimposed by mirror operation, shown by the broken line in Fig. 16. As a result, macroscopic morphology and surface structure differ between left- and right-handed $\alpha$-CO.

\section{OUTLOOK}

The present studies showed that icy interstellar grains, which were mainly composed of $\mathrm{CO}$ and $\mathrm{H}_{2} \mathrm{O}$, were not spherical with an onion structure as hitherto assumed but rather a polyhedral chiral $\alpha-\mathrm{CO}$ attached to am- $\mathrm{H}_{2} \mathrm{O}$. This finding has important implications for the direction of future research on this topic. We will mention some implications although some of these are speculative.

Numerous theoretical studies have detailed the formation and evolution of ice on interstellar dust grain surfaces in star-forming regions by using chemical reaction network models (see Cuppen et al. 2017 for a recent review). In the vast majority of these studies, it was assumed that the ice grains were spherical and that each chemical species was characterized by a single binding energy and a surface diffusion activation energy barrier with values appropriate for the am- $\mathrm{H}_{2} \mathrm{O}$ surface. However, our study has shown that solid $\mathrm{CO}$ was crystalline and that the different surface chemical reactions proceed simultaneously on the am- $\mathrm{H}_{2} \mathrm{O}$ and the $\alpha$-CO. Although there were no data on the adsorption and surface diffusion of atoms, radicals, and molecules on the molecularly flat surface of $\alpha-\mathrm{CO}$, there was a possibility that these values differed greatly from those obtained on am- $\mathrm{H}_{2} \mathrm{O}$. Measuring these values on the $\alpha-\mathrm{CO}$ or estimating them is highly desirable. Furthermore, it should be noted that the non-thermal desorption of molecules or radicals from the am- $\mathrm{H}_{2} \mathrm{O}$ and $\alpha-\mathrm{CO}$ surfaces occurred simultaneously. The photodesorption of $\mathrm{H}_{2} \mathrm{O}$ molecules also took place (Hama et al. 2010; Hama, Kouchi \& Watanabe 2016), in spite of the occurrence of solid $\mathrm{CO}$, because the bare surface of am- $\mathrm{H}_{2} \mathrm{O}$ was exposed. This could 
explain the detection of $\mathrm{H}_{2} \mathrm{O}$ vapour in the centre of the pre-stellar core of L1544, where CO freeze-out was significant (Caselli et al. 2012).

The collision and subsequent sticking or fragmentation of grains or grain aggregates are important elemental processes to discuss when studying the formation of planetesimals in protoplanetary discs. Theoretical models for collisions usually assumed that the grains' morphology was spherical (Dominik \& Tielens 1997; Wada et al. 2007), and, as such, most laboratory experiments for particle collisions used spherical samples (Blum \& Wurm 2000; Gundlach \& Blum 2015; Gärtner et al. 2017). However, Poppe et al. (2000) demonstrated that the sticking probability of irregularly shaped grains was a weak function of the collision velocity, with some sticking collisions occurring even at high-collision velocities. This suggested that even simple collision models that assume the presence of spherical grains may not accurately capture the sticking properties of irregularly shaped grains or the attached am- $\mathrm{H}_{2} \mathrm{O}$ grains. The stickiness of $\mathrm{CO}, \mathrm{CO}_{2}$, and $\mathrm{H}_{2} \mathrm{O}$ ice groups in protoplanetary discs could be determined by understanding the morphologies of crystalline $\mathrm{CO}_{2}$ and $\mathrm{H}_{2} \mathrm{O}$, as demonstrated in the present study.

Biological homochirality is one of the unsolved mysteries surrounding the origin of life. Here, the proposed mechanisms for the homochirality of organic molecules suggested the occurrence of chiral selection on inorganic chiral crystals such as quartz and cinnabar (Hazen \& Sholl 2003; Weissbuch \& Lahav 2011; Soai 2019). Since these minerals could be formed only in evolved bodies such as meteoritic parent bodies and terrestrial planets, it was shown that there was no chiral crystal in interstellar grains. However, the present study clearly showed the possible presence of chiral CO crystals in molecular clouds. When one-handed circularly polarized light, which has been emitted from various sources (Bonner 1991; Bailey et al. 1998), was used to irradiate ice grains with nanoparticles during $\alpha-\mathrm{CO}$ formation, the resulting crystal enantiomeric excess might be several tens of per cent. This suggestion could be supported by laboratory experiments on $\mathrm{NaClO}_{3}$ chiral crystallization (Niinomi et al. 2016; Cheng et al. 2020) and theoretical studies (Tang \& Cohen 2010; Liu et al. 2015; Ho et al. 2016). The peak attributed to circular dichroism of the chiral molecule, which generally lies in UV region, could be transferred to the visible wavelength region in these cases (Zhang \& Govorov 2013; Wang et al. 2014; Vestler, Ben-Moshe \& Markovich 2019). Asymmetric synthesis and/or asymmetric adsorption might be shown to proceed efficiently on the surface of the one-handed $\alpha$-CO. Our present study expands the scientific quest of homochirality in space.

The origin of homochirality in interstellar organic molecules was described in light of asymmetric photolysis (Greenberg et al. 1994; Meierhenrich et al. 2005) or asymmetric synthesis (Takano et al. 2007; Modica et al. 2014) in organic molecules via exposure to circularly polarized UV. Additionally, the enantiomeric excesses obtained in these experiments were 2 percent at most. However, this idea has the difficulty of UV penetration into molecular clouds or protoplanetary discs. As mentioned above, the problem could be resolved by using circularly polarized 'visible' light with nanoparticles on grains. In this case, the enantiomeric excesses might improve by several tens of a per cent.

\section{ACKNOWLEDGEMENTS}

This work was supported by the grant for Joint Research Program of the Institute of Low Temperature Science, Hokkaido University (18K001), the Ministry of Education, Culture, Sports, Science and Technology Grants-in-Aid for Scientific Research (KAKENHI; grant no. JP25108002), and the Japan Society for the Promotion of Science Grants-in-Aid for Scientific Research (KAKENHI; grant no. JP17H06087).

\section{DATA AVAILABILITY}

The data underlying this article will be shared on reasonable request to the corresponding author.

\section{REFERENCES}

Accolla M. et al. 2011, PCCP, 13, 8037

Atake T., Suga H., Chihara H., 1976, Chem. Lett., 567

Bailey J., Chrysostomou A., Hough J. H., Gledhill T. M., McCall A., Clark

S., Menard F., Tamura M., 1998, Science 281, 672

Baragiola R.A., 2003, Planet. Space Sci., 51, 953

Barrata G.A., Palumbo M.E., 2017, A\&A, 608, A81

Bhakta A., Ruckenstein E., 1995, J. Chem. Phys., 103, 7120

Blum J., Wurm G., 2000, Icarus, 143, 138

Bonner W.A., 1991, Orig. Life Evol. Biosph., 21, 59

Boogert A.C.A., Gerakines P.A., Whittet D.C.B. 2015, ARA\&A, 53, 541

Caselli P. et al., 2012, ApJ. 759, L37

Cheng A.-C. et al., 2020, J. Phys. Chem. Lett., 11, 4422

Ciesla F., 2014, ApJ, 784, L1

Collings M.P, Dever J.W., Fraser H.J., McCoustra M.R.S., Williams D.A., 2003, ApJ, 583, 1058

Cuppen H.M., Walsh C., Lamberts T., Semenov D., Garrod R. T., Penteado E. M., Ioppolo S., 2017, Space Sci. Rev., 212, 1

Dominik C., Tielens A.G.G.M., 1997, ApJ, 480, 647

Dulieu F., Amiaud L., Congiu E., Fillion J.-H., Matar E., Momeni A., Pirronello V., Lemaire J. L., 2010, A\&A, 512, A30

Ehrenfreund P., Dartois E., Demyk K., d'Hendecourt L., 1998, A\&A, 339, L17

Escribano R.M., Muñoz Caro G.M., Cruz-Diaz G.A., Rodríguez-Lazcano Y., Matéa B., 2013, Proc. Natl. Acad. Sci., 110, 12899

Famá M., Loeffler M.J., Raut U., Baragiola R.A., 2010, Icarus, 207, 314

Fayolle E.C., Balfe J., Loomis R., Bergner J., Graninger D., Rajappan M., Öberg K. I., 2016, ApJ, 816, L28

Furuya K., Aikawa Y., Hincelin U., Hassel G. E., Bergin E. A., Vasyunin A. I., Herbst E., 2015, A\&A, 584, A124

Garrod R.T., Pauly T., 2011, ApJ, 735, 15

Gärtner S. et al. 2017, ApJ, 848, 96

Gerakines P.A., Hudson R.L., 2015, ApJ, 808, L40.

Gibb E.L., Whittet D.C.B., Boogert A.C.A., Tielens A.G.G.M., 2004, ApJS, 151,35

Greenberg J.M. et al., 1994, J. Biol. Phys., 20, 61

Gundlach B., Blum J., 2015, ApJ, 798, 34

Hama T. et al., 2010, J. Chem. Phys., 132, 164508

Hama T., Watanabe N., 2013, Chem. Rev., 113, 8783

Hama T., Kouchi A., Watanabe N., 2016, Science, 351, 65

Hazen R.M., Sholl D.S., 2003, Nat. Mater., 2, 367

He J., Vidali G., 2018, Mon. Not. R. Astron. Soc., 473, 860

Heide H.-G., 1984, Ultramicroscopy, 14, 271

Heide H.-G., Zeitler E., 1985, Ultramicroscopy, 16, 151

Ho C-S., García-Extarri A., Zhao Y., Dionne J., 2016, ACS Photonics, 4, 197

Ioppolo S., Cuppen H. M., Romanzin C., van Dishoeck E. F., Linnartz H., 2008, ApJ, 686, 1474

Jenniskens P., Blake D.F., 1996, ApJ, 473, 1104

Kouchi A., 1990, J. Cryst. Growth, 99, 1220

Kouchi A., Kuroda T., 1990, Nature, 344, 134

Kouchi A., Yamamoto T., Kozasa T., Kuroda T., Greenberg J.M., 1994, A\&A, 290, 1009

Kouchi A., Hama T., Kimura Y., Hidaka H., Escribano R., Watanabe N., 2016, Chem. Phys. Lett., 658, 287

Kouchi A., Furuya K., Hama T., Chigai T., Kozasa T., Watanabe N., 2020, ApJ, 891, L22 
Kovalenko S.I., Indan E.I., Khudotyoplaya A.A., Krupskii I.N., 1973, Phys. Status Solidi A, 20, 629

Leto G., Baratta G.A., 2003, A\&A, 397, 7

Li F., Brookeman J.R., Rigamonti A., Scott T.A., 1981, J. Chem. Phys., 74, 3120

Li A., Greenberg J.M., 1997, A\&A, 323, 566.

Liu Y., Zhao W., Ji Y., Wang R.-Y., Wu X., Zhang X. D., 2015, Europhys. Lett., 110, 17008

Mastrapa R. M. E., Grundy W. M., Gudipati M. S., 2013, in Gudipati M. S., Castillo-Rogez J., eds, The Science of Solar System Ices. Springer, New York, p. 371

Maté B., Rodoríguez-Lazcano Y., Herreo V.J., 2012, PCCP, 14, 10595

Meierhenrich U.J. et al., 2005, Angew. Chem. Int. Ed. 44, 5630

Miyauchi N., Hidaka H., Chigai T., Nagaoka A., Watanabe N., Kouchi A., 2008, Chem. Phys. Lett., 456, 27

Mizuno Y., Kofu M., Yamamuro O., 2016, J. Phys. Soc. Japan, 85, 124602

Modica P., Meinert C., de Marcellus P., Nahon L., Meierhenrich U. J., Le Sergeant d'Hendecourt L., 2014, ApJ, 788, 79

Moore M.L., Hudson R.L., 1992, ApJ, 401, 353

Musiolik G., Teiser J., Jankowski T., Wurm G., 2016, ApJ, 818, 16

Niinomi H. et al., 2016, CrystEngComm, 18, 7441

Noble J.A. et al. 2012, MNRAS, 421, 768

Oba Y., Miyauchi N., Hidaka H., Chigai T., Watanabe N., Kouchi A., 2009, ApJ, 701, 464

Oba Y., Watanabe N., Kouchi A., Hama T., Pirronello V., 2010, ApJ, 712, L174

Oba Y., Watanabe N., Hama T., Kuwahata K., Hidaka H., Kouchi A., 2012, ApJ, 749, 67

O’berg K., 2016, Chem. Rev., 116, 9631

Okuzumi S., Momose M., Sirono S.-I., Kobayashi H., Tanaka H., 2016, ApJ, 821,82

Palumbo M.E. 2006, A\&A, 453, 903

Pontoppidan K.M. et al., 2003, A\&A, 408, 981

Poppe T., Blum J., Henning Th., 2000, ApJ, 533, 454

Reimer L., Kohl H. 2008, Transmission Electron Microscopy, 5th Ed., Springer, New York
Ruad M., Wakelam V., Hersant F., 2016, Mon. Not. R. Astron. Soc., 459, 3756

Sandford S.A., Allamandola L.J., 1988, Icarus, 76, 201

Schmitt B., Grim R., Greenberg J.M., , 1989, 22nd Eslab Symposium on Infrared Spectroscopy in Astronomy, Eur. Space Agency, Noordwijk, p. 213

Sirono S., 1999, A\&A, 347, 720

Sirono S. -I., 2011, ApJ, 735, 131

Smith D.L., 1995, Thin-Film Deposition. McGraw-Hill, Boston, MA

Soai K., 2019, Proc. Japan Acad. Ser. B, 95, 89

Stevenson K.P., Kimmel G. A., Dohnalek Z., Smith R. S., Kay B. D., 1999 , Science, 283, 1505

Strazzula G., Baratta G.A., Leto G., Foti G., 1992, Europhys. Lett., 18, 517

Tachibana S. et al., 2017, Sci. Adv., 3, eaao2538

Takano Y. et al., 2007, Earth Planet. Sci. Lett. 254, 106

Tang Y., Cohen A.E., 2010, Phys. Rev. Lett., 104, 163901

Toschev S., 1973, in Hartman P. ed. Crystal Growth: An Introduction. NorthHolland, Amsterdam, p. 328

Tsuge M. et al., 2020, Chem. Phys. Lett., 760, 137999

Urso R.G., Scirè C., Baratta G.A., Compagnini G., Palumbo M.E., 2016, A\&A, 594, A80

Vegard L., 1930, Zeitschrift fi $i \frac{1}{2}$ r Physik, 61, 185

Vestler D., Ben-Moshe A., Markovich G., 2019, J. Phys. Chem. C, 123, 5017

Voorhees P.W., 1985, J. Stat. Phys., 38, 231

Wada K., Tanaka H., Suyama T., Kimura H., Yamamoto T., 2007, ApJ, 661, 320

Wang R.-Y. et al., 2014, J. Phys. Chem. C, 118, 9690

Wang L., Sun C., Xu H., Zhang J., Zhao Y., Guo W., Zhu J., 2020, AIP Adv., 10,045301

Watanabe N., Kouchi A., 2002, ApJ, 571, L173

Weissbuch I., Lahav M., 2011, Chem. Rev., 111, 3236

Zhang H., Govorov A.O., 2013, Phys. Rev. B 87, 075410

This paper has been typeset from a Microsoft Word file prepared by the author. 